\title{
ESTUDO DA UTILIZAÇÃO DE ESTIMADORES COM PROBLEMAS DE ESTIMABILIDADE E APLICAÇÕES
}

\author{
PAULO AFONSO BRACARENSE COSTA
}

Bacharel em Estatística

Orientador: Prof. Dr. EUCLYDES CUSTÓDIO DE LIMA FILHO

Dissertação apresentada à Escola Superior de Agricultura "Luiz de Queiroz", da Universidade de São Paulo, para obtenção do título de Mestre em Agronomia, Área de Concentração: Estatístlca e Experimentação Agronômlca.

P I R A C I C A B A

Estado de São Paulo - Brasil

Janeiro de 1995 
Fiche catelografica preparada pela Seçás de livros da

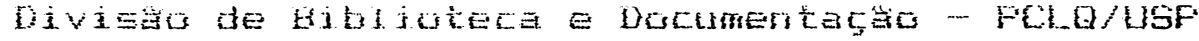

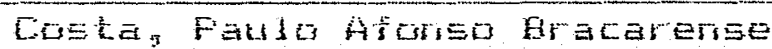

Cas7e Estudo da utilizacas de estimadores com problemas

dE Estimabilidade e aplicafoes. Firacicaba. 1995.

11.p. ilus.

Dis 5 - (HESTHE) - ESALE

Bibliografia.

1. Estatistica matemática 2. Madelo de Gaus-Markov 3. Hodelo matematica 1. Escola Superior de Agricultura Luiz de Queiroz, Firacicaba

COD 519.5 


\section{ESTUDO DÁ UTILIZȦÇÃO DE ESTIMADORES COM PROBLEMAS DE ESTIMÁBILIDȦDE E APLICAÇÕES}

PAULO AFONSO BRACARENSE COSTA

Aprovado em 24/03/95

Comissão Julgadora:

Prof. Dr. Euclydes Custódio de LImà Filho.

UNICAMP

Prof. Dr. Antonlo Franclsco lemma

ESALQ - USP

Prof. Dr. Anselmo Chaves Neto

UFPR

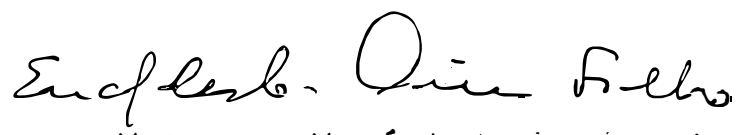

Prof. Dr. EUCLYDES CUSTÓDIO DE LIMA FILHO Orientador 
A meu pai $C$ in memorian?

A mi nha mãe $e$ a meus irmãos,

\section{ofereço.}

A Sandra e Natália,

dedico.

"HOMO SUM, HUMANI NIHIL A ME ALIENUM PUTO. “ 
Ao Prof. Dr. Euclydes Custódio de Lima Filho, pela orientacão e pela paciência.

Ao Prof. Dr. Antônio Francisco Iemma, pelos primeiros passos em Modelos Lineares.

Ao Prof. Dr. Ansel mo Chaves Neto, quem primeiro nos fez trilhar os caminhos acadêmi cos.

À Profa. Dra. Zélia Milléo Pavão, minha mentora intel ect.ual.

Ao Prof. Dr.Décio Barbin, exemplo de postura profissional e pessoal invejáveis.

Ao Prof. Dr. Luiz Gonzaga Caleffe, pelos ensinamentos em Metodologia de Pesquisa e pela redacão do SUMMARY .

Aos professores, colegas e funcionărios da ESALQ USP.

A Uni versidade Estadual de Ponta Grossa, pelo incenti vo e conf $i$ anca.

À Universidade Federal do Paraná, pelo apoio.

À Coordenação de Aperfeicoamento de Pessoal de Nível Superior - CAPES, pela bolsa de estudos (PICD).

A Rosa e à Iza pela amizade, pelo apoio, e pelo estímulo durante todo o curso. Sem elas está história não teria sido escrita desta forma. 
Ao Paulo Justiniano, companheiro do ostudo, pelas infindáveis e proveitosas discussões.

Ao Roberto Fernandez, pelo apoio computacional que foi alóm do profissionalismo.

Ao Alexandre Brocca, pelo incentivo desinteressado.

$$
\text { Aos meus alunos, pela manifestacão carinhosa }
$$

de apoio.

A minha esposa Sandra, pelos constantes estimulos, solidariedade paciência. 
Păgina

RESUMO $\ldots \ldots \ldots \ldots \ldots \ldots \ldots \ldots \ldots \ldots \ldots \ldots \ldots \ldots \ldots \ldots$

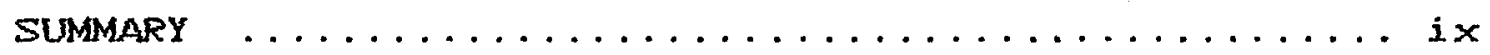

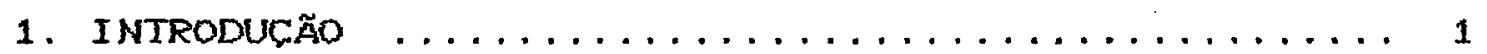

2. REVISÃO DE LITERATURA $\ldots \ldots \ldots \ldots \ldots \ldots \ldots \ldots \ldots \ldots \ldots$

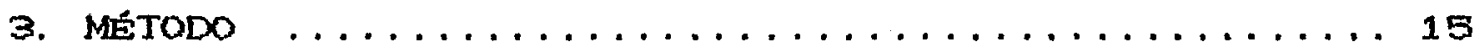

3.1. Decomposicão em Valores Singulares da Matriz X. 15

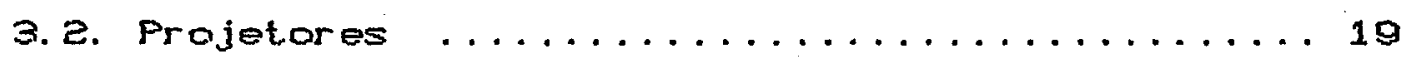

3.2.1. Projetores ortogonais ............ 19

3.2.2. Projetores Ortogonais e Matrizes ..... 2T

3.2.2.1. A Inversa de Moore-Penrose .... 31

3.3. o Modelo Linear $\ldots \ldots \ldots \ldots \ldots$

3. 3.1. O Problema de Míni mos Quadrados ....... 38

3.3.1.1. A Soluçăo por Equacões Normais. 41

3. 3.2. Projetores Ortogonais o Modelo Linear. 43

3. 3.3. Modelos Lineares e a DVS ...........47

3. 4. Estimabilidade ................... 51

3. 4.1. Estimabilidade no Madelo de Gauss-Markov 51

3. 4.2. Leitura pela DVS ............... S5

3. 5. Multicolinearidade ...................

3.5.1. Regressão por Componentes Principais .. 80

3.5.1.1. o Método $\ldots \ldots \ldots \ldots \ldots$.

3.5.1.2. Multicolinearidade e seus efeitos na Regressão ........63

3.5.1.3. Quase - Multicolinearidade ... 68

3. 5.2. Di agnóstico ................ 71

3. 5. 2. 1. o Número de Condicão ....... 71 
3. \$. 2.2. Decomposi cão da variância do'

$$
\text { Coeficiente de Regressão } \ldots . .74
$$

3. B. Estimacão viciada $\ldots \ldots \ldots \ldots \ldots \ldots \ldots$

3.B.1. Avaliacão do erro na Estimacão viciada $\quad \ldots \ldots \ldots \ldots \ldots \ldots \ldots$

3.7. Um Exemplo ....................... $8 \mathrm{z}$

3.7.1. Delimitação do Problema ...... 82

3.7.2. Estudo da Multicolinearidade ...83

4. CONCLUSÖES $\ldots \ldots \ldots \ldots \ldots \ldots \ldots \ldots \ldots \ldots$

5. REFERENCIAS BIBLIOGRAFICAS $\ldots \ldots \ldots \ldots \ldots$

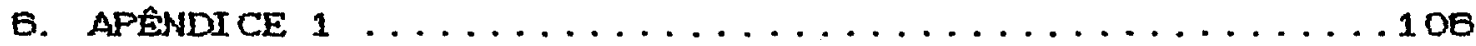

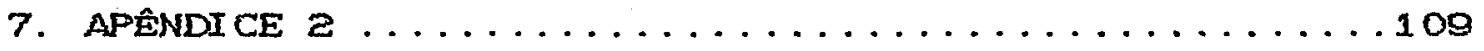




\title{
ESTUDO DA UTILIZACÃO DE ESTIMADORES COM PROBLEMAS DE ESTIMABILIDADE E APLICACÖES
}

\author{
Autor: Paulo afonso Bracarense costa \\ Orientador: Euclydes Custódio de Lima Fumo
}

RESUMO

No presente trabalho, objetivou-se avaliar a importância do erro que se comete ao se tomar estimadores viciados dos parámetros do particular modelo linear de regressão múl tipla.

Algumas combinacões 1 ineares dos parâmetros $(\lambda \cdot \beta)$ são determinadas através de combinaçóes 1 ineares dos dados observados. Nesto contexto adota-se a definifão de RAO (1945) que a função linear $\lambda^{\prime} \beta$ é 1 inearmente estimável se existe um vetor " $a$ " tal que ECa' $y$ ' $=\lambda$ ' $\beta$, para todos os possíveis $\beta E \mathbb{R}^{p}$, ou seja, se $\alpha^{\prime} y$ ' um estimador não tendencioso de $\lambda$ ' $\beta$.

Ocorre, no entanto, que muitas vezes, não possivel encontrar combinaços 1 ineares que obedecam os pressupostos do Teorema de Gauss-Markov. E nestas circunstâncias, os parâmetros não săo estimáveis, $\odot$ o 
problema não pode mais ser estudado no contexto da teoria de model os 1 i neares.

Foi raalizada uma avaliaçăo da importância do erro que se comete ao se tomarem combinacöes 1 ineares $\left(a^{\prime} y\right)$ que não obedecessem àquel es pressupostos o buscar solucbes que contornassem o problema de estimabilidade. Foi veriflcada entăo a possibilidade de se trabalhar com "quase-estimabilidade", conceito que pode ser compreendido quando se toma $\lambda$ bastante "próximo" do espaco-linha da matriz $X$ do modelo. 0 método utilizado fol o da decomposicão en valores singulares (DVS) da matriz do modelo. Através dele foi possivel compreender a estrutura da matriz o obter algoritmos estáveis para os cálculos realizados.

$$
\text { Foi apresentada uma aplicacão em }
$$

bi pestatistica, en un estudo de diabete. 


\title{
STUDY OF THE USE OF ESTIMATORS WITH ESTIBABILITY PROBLEMS AND APPLICATIONS
}

\author{
Author: Paulo afonso Bracarense costa \\ AdVISER: EuClydes Custódio de Lima Filho
}

SUMMARY

The purpose of this study was to evaluate the importance of the error that is associated with the use of biased estimators of the parameters of the particular multiple regression linear model.

Some linear combinations of the parameters $C \lambda$ ' $\beta$ are determined by means of 1 inear combinations of the observed data. In this context, it adopts the definition of RAO (1945) that the linear function $\lambda$ ' $\beta$ is linearly estimable if there exist a vector " $a$ " such that E(a'y) = $\lambda \cdot \beta$ for all possible $\beta \in \mathbb{R}^{P}$, that is, if $a^{\prime} y$ is a non biased estimator of $\lambda^{\prime} \beta$.

However, it is not always possible to determine Iinear combinations that comply with the assumptions of the Gauss-Markov Theorem. Under these circumstances, the parameter are no longer estimable and the 
problem can not be studied within the context of the linear model theory. -

An evaluation of the importance of the error associated with the use of 1 inear combinations (a'y) that do not meet those assumptions was undertaken. This was followed by the search for solutions to the problem of estibability. The possibility of using the concept of "quasi-estimability" was then analyzed. This concept can be understood as a great proximity of $\lambda$ to the row-space of the $X$ matrix of the model. The method uses the singular value decomposition CSVD of the matrix and which makes avallable a stable algorithm for the necessary calculations.

An application in biostatistics, in a study of diabetes, was presented. 


\section{INTRODUCAO}

Análises de modelos são técnicas estatísticas para pesquisar descrever a relacăo entre variáveis. Suas aplicacões são numerosas e ocorrem em quase todos os campos da ciência. Um dos seus objetivos consiste em explicar um fenòmeno real através de um modelo matemático.

Se y é uma variável que deve ser descrita através de um conjunto de fatores $x_{1}, x_{2}, \ldots, x_{n}$, então $y=$ $f\left(x_{1}, x_{2}, \ldots, x_{n}, \varepsilon=f(x, \varepsilon)\right.$ onde $\varepsilon$ representa um conjunto provavelmente, grande de outros fatores năo considerados, e gue se convencionou chamar de residuo ou erro.

Seja, por exemplo, o modelo de regressão linear simples, $y=\beta_{0}+\beta_{1} x+\varepsilon$, que explica a relacão entre as variáveis $x \in y$. Então, tomando-se os dados de uma amostra, pode-se obter informacóes sobre os valores dos parâmetros $\beta_{D}$ e $\beta_{2}$ através de seus estimadores de mínimos quadrados $\hat{\beta}_{0} \quad \theta \hat{\beta}_{2}$, técnica fartamente utilizada $\theta$ de domínio comum. 
A justificativa principal para a utilizacão do método dos mínimos quadrados para estimar uma regressão linear é dada pelo Teorema de Gauss-Markov. Este teorema garante que na classe dos estimadores lineares não tendenciosos de $\beta$, o estimador $\hat{\beta}$ de quadrados minimos é o que tem variância minima. Istó, é, é o melhor estimador linear não tendencioso CBLUE - "Best Linear Unbiased Estimator"?.

Algumas combinaçốes lineares dos parámetros $C \lambda$ ' $\beta$ sâo determinadas através de combinaç̋es lineares dos dados observados. Define-se então, que a funcâo 1 inear $\lambda$ ' $\beta$ E linearmente estimável se existe um vetor "a" tal que

$$
E\left(a^{*} y\right)=\lambda \cdot \beta
$$

para todos os possíveis $\beta \in \mathbb{R}^{p}$, ou seja, se a'y é um estimador não tendencioso de $\lambda^{\prime} \beta$, onde $p$ é o número de parâmetros.

ocorre, no entanto, que muitas vezes năo possivel encontrar combinacöes lineares que obedecam aos pressupostos do Teorema de Gauss-Markov. E nestas circunstâncias, os parâmetros năo săo estimáveis, e o problema não pode mais ser estudado no contexto da teoria de modelos 1 ineares.

E ainda, dizer que a funçấo linear $\lambda$ ' $\beta$ é linearmente estimável se $a^{\prime} y$ b́ um estimador não tendencioso 
de $\lambda^{\prime} \beta$ é fundamentalmente um problema de natureza matemática. Assim, é de grande interesse buscar métodos que proporcionem estabilidade numérica na solucão das equacôes 1 i neares.

o objetivo deste trabalho a avaliar a Importancia do erro que se comete ao se tomarem combinacões lineares $\left(a^{\prime} y\right)$ que năo obedecam aos pressupostos do Teorema de Gauss-Markov, e buscar solucóes que contornem o problema de estimabilidade. Será verificada então a possibilidade do se trabalhar com "quase-estimabilidade", conceito que pode ser compreendido quando se tom $\lambda$ próximo do espaco-linha da matriz $X$ do modelo. Para tanto utiliza-se o método da decomposicão em valores singulares (DVS) da matriz do modelo visando obter algoritmos estáveis para o cálculo da aproximacão. Ademais, com o objetivo de ilustrar os procedimentos adotados, apresenta-se uma aplicacăo em un problema real em bi oestatistica. 


\section{REVISÄO DE LITERATURA}

o problema de multicoli nearidade em regressão E fundamental mente o do mal-condicionamento da matriz $X$ do modelo linear. Ele ocorre quando solunas da matriz $x$, que são os dados amostrais dos preditores ou variáveis independentes, ou combinacôes 1 ineares delas são altamente correl aci onadas.

A multicolinearidade pode ser compreendida pelo estudo de (i) suas causas, (ii) seu efejto, (iii) seu diagnóstico (iv) possiveis solucóes para o problema de mul ticoli neari dade.

\section{(i) MONTGOMERY E PECK (1981) sugerem como} possiveis causas de multicolinearidade : o métado utilizado na obtenção dos dados, as restricôes sobre o modelo, a especificacão do modelo e modelos super parametrizados. As recomendacóos para a análise de dados e interpretaçăo do modelo resultante depende muito da causa do problema. Esta questão é discutida em detalhes por MASON, GUNST E WEBSTER (1975). Os autores tamhém afirmam que a questão de multicolinearidade é mais uma questão de seu grau, do que simplesmente de sua existência. 
Para NETER, WASSERMAN E KUTNER (1983), as variáveis independentes tendem a ser correlacionadas entre si em muitas situacốes não experimentais, tais como, em ciências sociais e biológicas, economia, financas dentre outras.

DRAPPER E SMITH C1981) pensam este problema de duas formas. Ou o modelo é super-especificado, isto é, mais parâmetros são postulados que os necessários para expressar os dados, ou os dados não săo adequados para estimar os parâmetros do modelo proposto.o que para eles, estas duas formas são "as faces de uma mesma moeda". Essencialmente o que se tem a fazer simplificar o modelo ou se for possivel, coletar dados que possibiliten a sua esti macão.

Ciis Para BELSLEY, KUH E WELSCH (1980), O virtual dano que resulta de dados provenientes de variáveis multicolineares, pode ser entendido intuitivamente constatando-se que tais variáveis não fornecem informacones que sejam muito diferentes daquelas já inerentes nas outras variáveis, e que portanto, fica dificil inferir sobre as influências individuais dessas variáveis independentes sobre a resposta. MONTGOMERY E FECK (1981) afirmam que a presenca de multicolinearidade acarreta sérios efeitos nas estimativas de minimos quadrados dos coeficientes de regressăo. A forte multicolinearidade entre dois preditores resulta em variâncias e covariâncias muito elevadas para os 
coeficientes da regressão, embora, esta não seja a única causa. HOERL E KENMARD c1970a most.ram quo a multicolinearidade também tende a produzir estimativas dos parâmetros que são muito grandes en valores absolutos, o que implica que a distância entre a estimativa e o verdadeiro valor do parámetro pode ser muito grande. o que não significa necessariamente que o modelo ajustado seja mal preditor, se a predicão ficar confinada a regiones do sub-espaco onde a multicolinearidade acontece aproximadamente. MANDEL (1982) corrobora esta opinião através da apresentacão do problema pela decomposicão em valores singulares da matriz de regressão.

Também, WEBSTER, GUNST E MASON (1974) indicam, entre outros problemas, que a multicolinearidade tende a produzir estimativas de minimos quadrados com variâncias muito grandes, visto gue $v(\hat{\beta})=C 1-R_{j}^{2} j^{-1} \alpha^{2}$, onde $R_{j}^{2} \stackrel{0}{ }$ coeficiente de determinacão múltipla da regressão de $\mathrm{x}_{\mathrm{j}}$ sobre as variáveis independentes restantes. BELSLEY, KUH E WELSCH (1980) ilustram o efeito da multicolinearidade em diverșas situacónes de mal condicionamento da matriz do modelo, mostrando que a perfeita colinearidade compromete a unicidade dos estimadores de quadrados mínimos. No caso da quase-mul ticolinearidade a equacão do hiper-plano é mal definida, o que se traduz estatisticamente para o fato que as estimativas de quadrados minimos $C o$ intercepto $e$ as 
inclinacóes parciaisł são imprecisas.

Ciij Mutos procedimentos têm sido empregados para detectar multicolinearidade. BELSLEY, KUH E WELSCH 1980 apresentam métodos mais usuais e seus respectivos problemas fraquezas. Entre eles estão: sinais hipotéticos dos coeficientes da regressão trocados, "importantes" preditores tem baixos valores da estatistica "ť" vários resultados da regressão são sensiveis à delecão de uma linha ou uma coluna da matriz X. NETER, WASSERMAN E KUTMER (1983) chamam estes métodos de informais - complementam a lista quando existem grandes alteracóses nos coeficientes de regressão estimados; quando uma variável é incluida ou excluida, ou quando uma observacão alterada ou retirada, e intervalos de confianca com grandes amplitudes, para coeficientes de regressão representando i mportantes variáveis independentes. Nos dois trabelhos, os autores observam que estes métodos informais têm limitaçốs importantes, por não serem condicöes necessárias ou suficientes para a existência de multicolinearidade e não avaliarem a intensidade nem identificarem a natureza da mul ti col i nearidade.

BELSLEY, KUH E WELSCH (1980) discutem também a utilizacão do exame da matriz de correlacão $R$ dos preditores ou de sua inversa $R^{-1}$. Afirmam que a falta de altas correlacóes não indica que não há problema de multicolinearidade. E ainda é possivel que três ou mais 
8.

variáveis sejam colineares enquanto duas a duas não apresentam esta situacão. o mesmo problema surge na proposicão do GHATTERJEE E PRICE (1977) da avaliacão da multicolinearidade pelos chamados fatores de inflacấ da

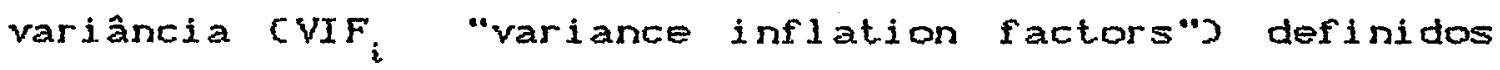
como

$$
V I F_{i}=\frac{1}{1-R_{i}^{2}}
$$

onde $R_{i}^{2}$ é coeficiente da correlacão múltipla de $x_{i}$ com os preditores remanescentes. Sua fraqueza está em sua incapacidade de distinguir entre muitas quase-colinearidades co-existentes. No entanto, NETER, WASSERMAN E KUTNER (1983) afirmam que experiências têm mostrado, que quando quaisquer dos VIF's excedem a 10 , isto pode ser tomado como uma indicacão de que os coeficientes de regressão associados a estes valores, têm estimativas de quadrados minimos demasiadamente influenciadas pela mul ticol ineari dade.

BELSLEY, KUH E WELSCH C1980), citam ainda a técnica de FARRAR E GLAUBER (19B7), que teve grande impacto em econometria e que encontraram uma medida de colinearidade baseada na assuncão que a matriz $x_{n \times p}$ é uma matriz de uma amostra de tamanho " $n$ " com "p" variáveis com distribuição normal. Além da utilizacão dos VIF's e de medida de desvio da ortogonalidade através da estatistica $x^{2}$ calculada a partir do determinante de $R$, a matriz de 
correlacăo. Os autores mostram, utilizando vários trabalhos de outros autores que estes métodos não são exatos para apontar multicoli nearidade.

MONTCOMERY E PECK 519813 apresentam no cálculo do determinante de $X^{\prime} X$ um possivel indicador de multicolinearidade quando este valor se aproxima de zero. Mas observam que este procedimento năo dá qualquer indicacão da fonte de multicol inearidade.

BELSLEY, KUH E WELSCH (1980) apontam que por muitos anos os autovalores autovetores de $X^{\wedge} \mathrm{X}$ ou sua correspondente matriz de correlacóes $R$ foi empregada para diagnosticar multicolinearidade. Cita os trabalhos de KENDALL (1957) E SILVEY (1909) que utilizam os autovalores de $X ' X$ como a chave da presenca de multicolinearidade, ou seja. "pequenos" autovalores seriam indicativos de multicolinearidade. A dificuldade que surge neste procedimento é determinar o significado de "pequeno", e a natural tendîncia de comparar "pequeno" com zoro.

Segundo MONTSOMERY E PECK $01981 \mathrm{l}$ as caracteristicas desejáveis de un procedimento de diagnóstico resume-se em refletir diretamente o grau de mul ticolinearidade do problema e fornecer informacótes úteis para determinar que variáreis independentes estão enval vidas. BELSLEY, KUH E WELSCH C1980) afirman que a base para o diagnóstico de multicolinearidade está no campo da análise numérica, que é capaz de colocar significado real 
para as medidas baseadas nos autovalores e apresenta a decomposicão em valores singulares da matriz $X$, que tom intima conexăo com o sistema de squacốs caracteristicas da. matriz X'X. Aplica o conceito de número de condicăo a decomposicão da variância dos coeficientes de regressão, discutidos em detal hes no corpo deste trabal ho.

(iv) MANDEL (1982), afirma que a grande diflculdade no uso de quadrados mínimos é a existência de colinearidade em muitos conjuntos de dados, que a maioria das modificacõos do método de mínimos quadrados ordinários se deveram ao estudo desta questăo. Cita como as principais técnicas para a solucăo deste problema a regressão por componentes principais, a regresăo peld análise de valores latentes ("latent root regression"), a regressão contraída ou "shrinkage" a regressão de cumeeira c"ridge regression"s. Uma discussão comparativa entre estas técnicas foi realizada por PALM E IEMMA (1994) incluindo ainda as técnicas de quadrados médios parciais e estl madores de James Stein.

HOERL \& KENNARD (1970) propuseram na solucão das equacóes de minimos quadrados $\left.\hat{\beta}=c X^{\prime} X\right)^{-1} x^{\prime} y$ para modelos de regressão não-ortogonais, a sol ução $\hat{\beta}=\left[X^{\prime} X+K I\right]^{-1} X^{\prime} y$ cestimador de cumeeira - "ridge estimator" onde $K$ é uma matriz diagonal de constantes não negativas. MARQUARDT E SNEE (197B) apresentam uma interpretacão geométrica da regressão de cumeeira para o 
caso hipotético envol vendo apenas dois parâmetros. HOCKING (1976) ressalta que grande parte da controvérsia, acerca da regressão de cumeeira está na escol ha do valor da constante K. FERRARI $(1989$ apresenta vários trabal hos de comparacões em busca de um método ótimo para a obtencão de $k$, destacando os seguintes: método baseado no teorema da existência, método baseado na estimacăo de $\beta^{\prime} \beta$, método iterativo, método de Lawless e Wang, método baseado na estatistica $C_{k}$ que envolve a soma de quadrados do residuo com o valor de $K$, o método baseado no traco da cumeeira.

- método chamado de análise de valores latentes cou "latent root regression"s desenvolvido por WEESTER, GUNST E MASON $(1974)$ é uma variante do método de componentes principais. Os autores sugerem calcular os componentes nâo a partir da matriz $X^{\prime} X$, mas a partir de A'A onde $A=\left[\begin{array}{ll}y & A\end{array}\right]$ incluindo assim a variável dependente dentro do cálculo dos componentes principais.

PALM E IEMMA (1994) discutem a regressão de mínimos quadrados parciais, que foi desenvol vido dentro do dominio da quimica, em relacão aos problemas de calibragem pOr MARTENS E NAES (1989). O método apresenta analogias com a regressão por componentes principais e a regressăo por valores latentes. Os autores discutem, ainda os estimadores de JAMES E STEIN (1961), que tem por objetivo encontrar um compromisso entre o vicio e a variância, a fim de minimizar a esperanca matemática do quadrado médio do erro sobre o 
vetor dos coeficientes da regressão.

MAYER \& WILE (1973) apresentam a classe dos estimadores viciados C"ridge estimators"s para os parametros de um modelo linear com matriz de delineamento mal condicionada, como uma sub-classe da classe das Eransformaçooses lineares dos estimadores de minimos quadrados, e apresentaram uma elasse alternativa de estimadores, rotulados de estimadores contraidos C"shrunken estimators"?.

LIMA FILHO C1981J discute uma forma de otimizar a estimacão de combinacões lineares de vetores de parâmetros no modelo linear utilizando observacões adicionais. Utiliza a decomposicäo em valores singulares da matriz de delineamento para indicar com detalhe a estrutura do modelo. Tal método pode ser utilizado para a avaliação de estimadores viciados, representando o espaco-col una CCXS - ospaco-linha CCX'S de modo a permitir a visualizacão das funç̋es estimáveis eventuais problemas nos dados e colinearidades nas colunas da matriz $X$. Além disso, a decomposicão em valores singulares da matriz $X$ fornece um modo numericamente estável de cálculo das quantidades de interesse na regressão proporciona um modo igualmente elementar de apresentar toda a teoria de Modelos Lineares. HAWKINS (1973), GREENEERG (1975), entre outros, propốm o uso da regressão em componentes principais, como procedimento alternativo ao de minimos 
quadrados, para situacöes en que as variáveis independentes são al tamente correlacionadas. Para a obtencão do estimador em componentes principais HOCKING, SPEED E LYNN (197B) consideram o modelo na forma canónica, onde as variáveis independentes no modelo são consideradas em ordem decrescente de seus autovalores, sendo que os últínos autovalores são próximos de zero, e são então excluídos da análise. Assim a regressão por componentes principais é obtida aplicando-se a técnica de minimos quadrados aos componentes restantes. Entre as vantagens da regressão por componentes principais, GUNST E MASON (1977b) apontam que tanto a teoria exata sobre as distribuicóes, como os procedimentos de selecão de variáveis estão disponí veis.

$$
\text { MANDEL (1982) analisa situacóes de }
$$

quase-multicolinearidade a partir da decomposicão em valores singulares da matriz $X$, procedimento correlato a regressão por componentes principais e avalia a vantagem de se tomar um estimador viciado para $\beta$, desdo que a variância das estimativas seja suficientemente menor do que para estimadores não viciados obtidos do método de minimos quadrados ordinários.

COOD (1989) mostra que o tratamento mais simplificado de inversas generalizadas é feito através da decomposiçăo em valores singulares da matriz X. A definiçăo da inversa generalizada a partir da DVS É sugestiva por ela mesma, e mais simples que a definicão dada por Moore 
14.

$(1920)^{1}$ - Penrose $(1955)^{2}$, que definem a inversa generalizada através de quatro propriedades. A existencia a unicidade são obtidas imediatamente da aplicacão da DVS

Do ponto de vista computaional o programa MATLAE é integrado entre outros módulos por um do análise numérica e outro de calculo matricial. Apresenta os resultados da DVS e os demais resultados numéricos com grande acurácia e é de fácil utilizacão.

1 MOORE, E. H. On the Jeciprocal of the general algebraic matrix. Aull. Am. Malh. Soc., 20: 304-05, 1020.

2 PENRDSE, RA. A generalized inverse for matrices. Proc. Cambridge Philos. soc. 51: $406-13,1055$. 
15.

\section{METODOS}

\subsection{DECOMPOSI CAO EM YALORES SINGULARES DA MATRIZ $x$}

Seja $x$ uma matriz nxp de posto $r \leq p$. Os valores $s_{1} \geq \ldots \geq s_{r}>0$, onde $\left.s_{i}^{2} c i=1, \ldots, r\right)$ sấo as raízes caracteristicas de $x^{\prime} x<$ de $\left.x X^{\prime}\right)$, săo definidos como valores singulares da matriz $X$.

Existem matrizes ortogonais $v(n \times n)$ e $V(p \times p) e$ a matriz $S(n \times s)$ com

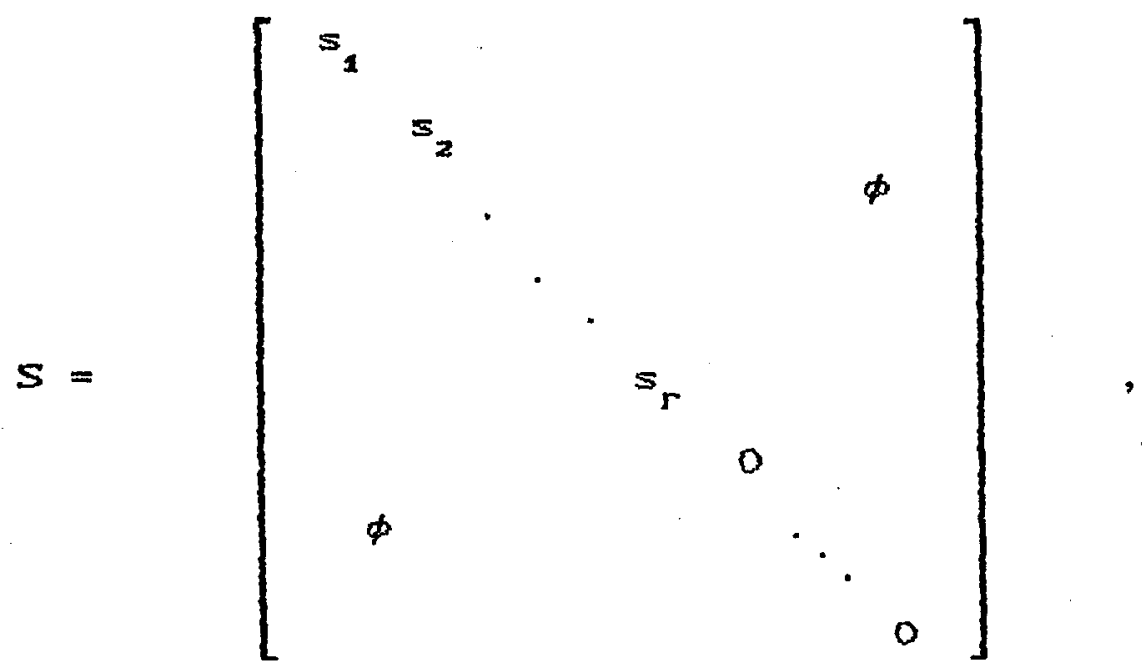

tais que,

$$
x_{n \times p}=U_{n \times n} S_{n \times p} V_{p \times p}^{\prime}
$$


18.

Este resultado obtido por ECKART $E$ YOUNG (1936) chamado de decomposicăo em valores singulares CDVS) da matriz $x$.

os vetores $u_{1}, u_{2}, \ldots, u_{r}, u_{r+1}, \ldots, u_{n}$, as $n$ colunas de $u$, são escolhidos como um conjunto do autovetores ortogonais normalizados de $\mathbf{X}$ ', correspondendo aos autovalores $s_{1}^{2}, s_{2}^{2}, \ldots, s_{t}^{2}, 0, \ldots, 0$ de $x x^{\prime}$.

Define-se

$$
U=\left[\begin{array}{lll}
u_{1} & u_{2}
\end{array}\right] ; \text { onde }
$$

$u_{i}=\left[u_{1}, u_{z}, \ldots, u_{r}\right]$ são os autovetores normalizados correspondentes aos autovalores não nulos de $x x, \quad s_{1}^{2}, s_{2}^{2}, \ldots, s_{r}^{2}$.

$E, \quad v_{2}=\left[u_{r+1} u_{r+2}, \ldots, u_{n}\right]$ são autovetores correspondentes aos autovalores nulos de $X X,, s_{r+1}^{2}, s_{T+2}^{2}$, $\cdots, s_{n}^{2}$.

Se $U_{i}$ um conjunto ortonormal de autovetores de $X^{\prime}$, correspondentes aos autovalores não nulos, ontão:

$$
x X, u_{i}=s_{i}^{2} u_{i}, i=1, \ldots, r .
$$

E, $r_{i}, i=1, \ldots, r$ pode ser definido como $v_{i}=\frac{1}{s_{i}} X^{3} u_{i}$, tendo-se então: 


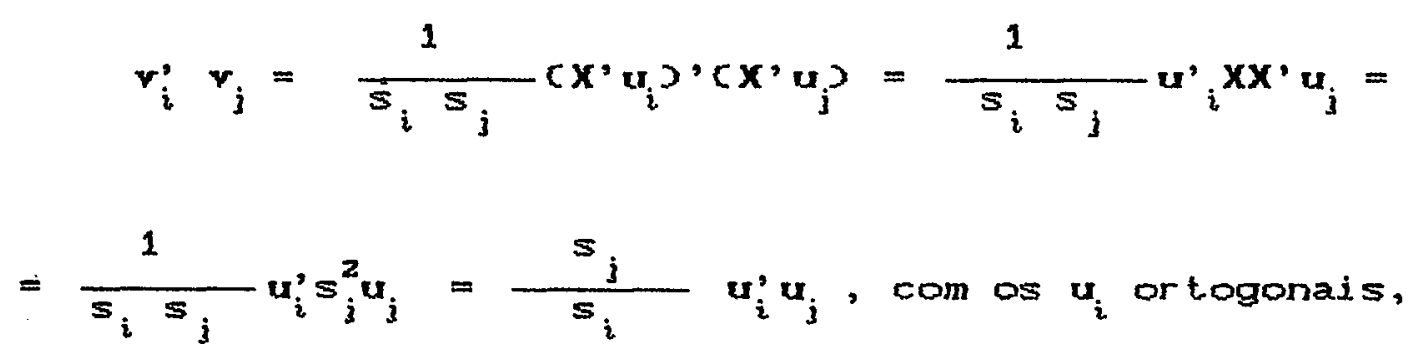

então, $\quad r_{i}^{\prime} r_{i}=\frac{s_{i}}{s_{j}} \delta_{i j}=\delta_{i j}^{\prime}$ onde $\delta_{i j}$ delta

de Kronecker

$$
v_{1}=\left[u_{2}, u_{2}, \ldots, u_{T}\right] \text { constitue uma base ortonormal }
$$

para CCX, o espaco coluna da matriz $X .\left[r_{2}, r_{2}, \ldots, r_{r}\right]$ onde

$v_{i}=\frac{1}{s_{i}} X^{\prime} u_{j}$, constitue uma base ortonormal para

CCX's, o espaco linha da matriz $X$.

$$
\left[u_{r+1}, u_{r+2}, \ldots, u_{n}\right] \text { constitue uma base }
$$

ortonormal para $C^{1}(X), 0$ espaço complemento ortogonal a $C(X)$ - $\left[\mathbf{v}_{r+1}, \mathbf{v}_{r+2}, \ldots \ldots, \mathbf{v}_{p}\right]$ constitue uma base ortonormal para $C^{\prime}(X)$, ospaco complemento ortogonal a CCX.'.

Tem-se por construção:

a) $u=\left[u_{1}\left\{u_{2}\right]=V=\left[v_{1} \mid v_{2}\right]\right.$ são ortogonais.

b) $x v_{2}=0 \quad x \cdot v_{2}=0$

$\cos X_{r_{j}}=0_{j}>x \in x^{\prime} u_{j}=0 j>r 3$ 
18.

Tomando a matriz $S=U^{\prime} X V=c s_{i j}$, obtém-se

$s_{i j}=u_{i}^{\prime} X r_{j}=0, j>r$ ou $i>r$.

Para $i<=r \notin j<=r$

$s_{i j}=u_{i} \times v_{j}=\frac{1}{s} u_{i}^{\prime} \times X^{\prime} u_{j}=\frac{s^{2}}{s} u_{i}^{\prime} u_{j}=s_{i} \delta_{i j}$

$\log 0$

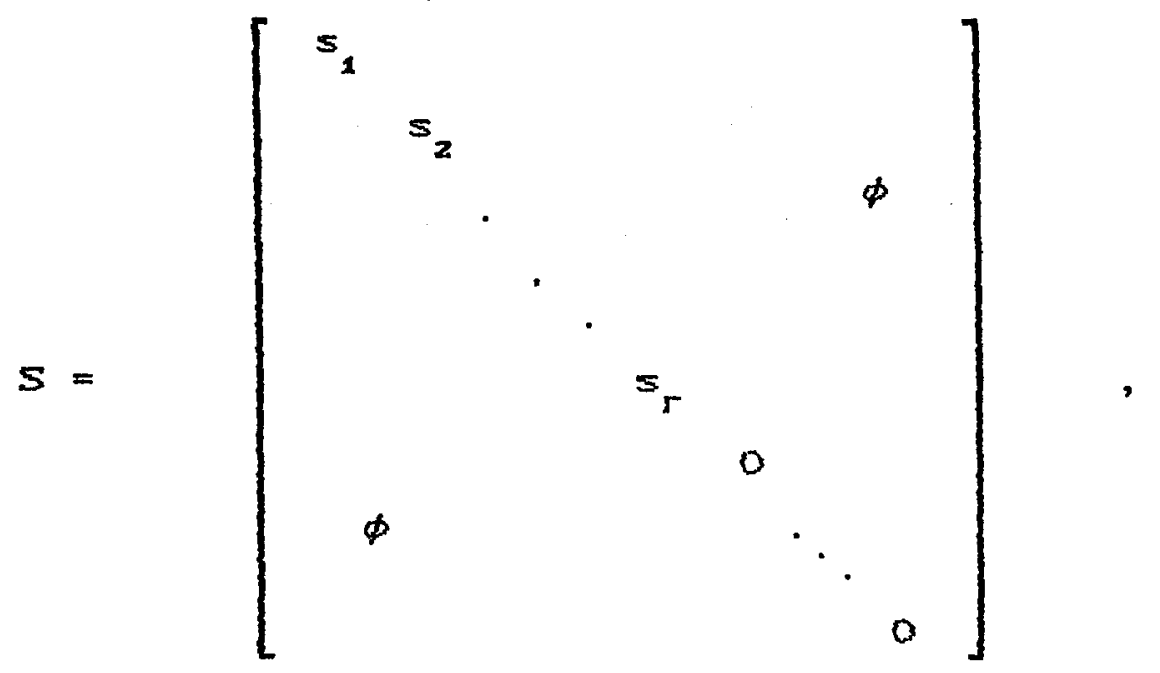

- que completa a demonstracão. 口

$x$ pode ser escrita como:

$$
X=U_{2} S_{i}
$$

onde $s_{1}=\operatorname{diag}\left(s_{1}, \ldots, s_{r} \supset\right.$, ou $x=\sum_{i=1}^{r} s_{i} u_{i} v_{i}^{\prime}$

A DVS está apresentada em detalhes em 
19.

BEN-ISRAEL E GREVILLE (1974). Seu cálculo exposto em detalhes por LAHSON E HANSON (1974). Um algoritmo fácil de cálculo está en GOLUE (1989). AOKI (1992) apresenta uma série de propriedades o teoremas da DVS.

\subsection{PROJETORES}

\subsubsection{PROJETORES ORTOGONAIS}

DEFINICAOO 3.2.1.1 Diz-Se que un espaco linear E É a soma direta dos subespacos $E_{1} \odot E_{2}$ e denota-se $E=E_{1} \oplus E_{2}$ se, - somente se, as seguintes condicóos forem satisfeitas:

$$
\text { (i) } E_{1} \subseteq E \odot E_{2} \leq E \text {; }
$$$$
\text { Ciis para cada } x \in E \text {, existe um } x_{1} E E_{1} \bullet x_{2} E
$$
$E_{2}$, tal que: $x=x_{1}+x_{2} e$;

$$
\text { (iii) se } x \in E_{1} \in x \in E_{2} \text { então } x=0 \text {. }
$$

A condicão $(i i i)$ é análoga a dizer que $E_{1} e$ $E_{2}$ săo virtualmente disjuntos, ou seja $E_{2} \cap E_{2}$ consisto somente do vetor nulo, o que implicará que a resolucăo descrita em (ii) é única. Pois, dado que:

$$
x \in E E x=x_{1}+x_{2}=y_{1}+y_{2},
$$

onde,

$$
x_{1}, y_{1} \in E_{1} \quad x_{2}, y_{2} \in E_{2},
$$

então 
20.

$x_{1}-y_{1}=x_{2}-y_{2}$, cono $x_{1}-y_{1} E E_{1} \theta x_{2}-y_{2} E E_{2}$

por Ciils implisa que:

$$
y_{1}=x_{1} \& y_{2}=x_{2} 0
$$

Se $E=E_{1} \oplus E_{2}$ diz-se que $E_{1} \oplus E_{2}$ são complementares, ou $E_{1}$ - complemento de $E_{2}$, ou $E_{2}$ : complemento de $E_{1}$. Além disso, se $\langle x, y\rangle=0$ Cproduto interno de $x \in y$ para todo $x \in E_{1} \in y \in E_{2}$ diz-se que $E_{1}$ complemento ortogonal de $E_{2}$, ou $E_{2}$ é complemento ortogonal do $E_{i}$.

DEFINIC̆̆O 3.2.1.2 Projetor: Considere um vetor arbitrário $x$ $\Theta E=E_{1} \oplus E_{2} e$ seja $x=x_{1}+x_{2}$ tal que $x_{1} \in E_{1}$ e $x_{2} E E_{2}$ onde $x_{1}$ e $x_{2}$ săo únicos. O mapeamento $P: x_{1}$ é chamado projetor de $E \odot m E_{1}$ na direcăo de $E_{z}$.

TEOREMA 3.2.1.1 Um operador linear $\mathrm{P} e$ um projetor se e somente se $\mathrm{P}$ é idempotente, ou seja, $\mathrm{P}^{2}=\mathrm{P}$.

Prova:

$C \Rightarrow$ SSeja $E$ um espaco linear, tal que $E=E_{1} \oplus E_{2}$ e $P$ um projetor de $E$ en $E_{1}$ na direcão de $E_{2}$. Então para todo $x_{2} E$ $E_{1}$ tem-se que $P\left(x_{1}\right)=x_{1}$ para todo $x_{2} \in E_{2}$ tem-se que $P\left(x_{2}\right)=0$.

Então para $x=E, x=x_{2}+x_{2}$ epor $C_{i}$ ili é único. $E$ portanto: 


$$
\begin{aligned}
P^{2}(x) & =P\left(P\left(x_{1}+x_{2}\right)=P\left(P\left(x_{1}\right)+P\left(x_{2}\right)\right)=\right. \\
& =P\left(x_{1}\right)=x_{1}=P(x) .
\end{aligned}
$$

C@Seja $x \in E$ onde $E_{2}=\operatorname{Im}(P)(i$ magem de $P), E_{2}=\operatorname{Ker}(P)$

(núcleo de P) $x_{1}=P\left(P(x) P=P^{2}(x)=P(x)=x_{1}\right.$.

Seja $x_{2}=x-x_{2}$. Então:

$P\left(x_{2}\right)=P\left(x-x_{1}\right)=P(x)-P\left(x_{1}\right)=x-x_{1}=0$.

Então $x=x_{1}+x_{2}$ onde $x_{1}=\operatorname{Im} \subset P \supset \in x_{2} \in \operatorname{Ker} C P S$. Claramente Im \& $P D \cap \operatorname{KerC} P J=0$ portanto $P$ um projetor de $E$ em $E_{1}$ na direcão de $E_{2}$.

$$
E_{2}
$$
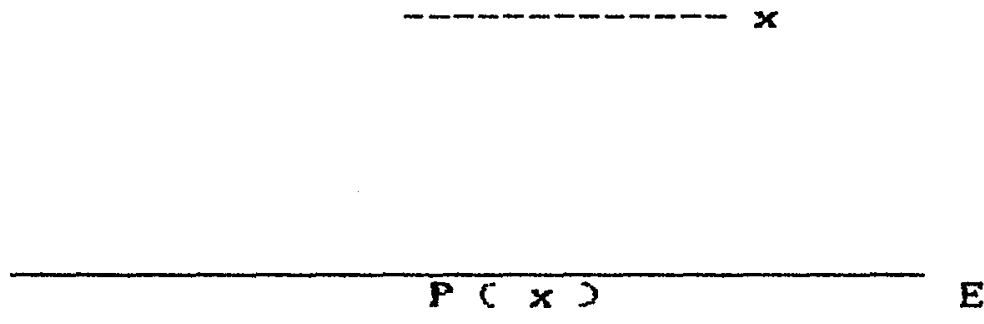

Fig. 3.2.1.1

No caso onde E o plano real a Fig. 3.2.1.1 indica a interpretacâo geométrica de projecão. 
2 2e.

Corolário 3.2.1.1 se P é o projetor de $\mathrm{E}$ em $E_{1}$ na direcão de $E_{2}$, então I - P E o projetor de $E$ em $E_{2}$ na direcão de $E_{1}$.

Prova:

Note que: $\quad C I-P S^{2}=I-2 P+P^{2}$

como $P^{2}=P$, então $(I-P)^{2}=(I-P)$

e portanto I - P é idempotente e I - P é projetor. Agora se $P$ é um projetor de $E$ em $E_{1}$ na direcão de $E_{2}$, tem-se que:

$$
P_{x}=x_{1}
$$

- portanto

$$
(1-P) x=x-P x=x_{1}+x_{2}-x_{1}=x_{2}
$$

ou seja, C I - P é um projetor de $E$ em $E_{2}$ na direcăo de $E_{1}$.

TEOREMA 3.2.1.2 Se P É idempotente, entăo:

a) $\operatorname{Im}(I-P)=\operatorname{Ker}(P)$

b) $\operatorname{Kar}(I-P)=\operatorname{Im}(P)$

Prova:

a) Se $x \in I m C I-P J$, então existe um $y \in C \subset$ onde $C \dot{e}$ um espaco linears, tal que $x=C I-P$ J. Então:

$$
P_{X}=P C I-P P_{Y}=P Y-P^{2} y=P y-P y=0
$$


29.

E portanto,

$$
\operatorname{Im}(I-P) \leq \operatorname{Ker}(P)
$$

Agora se $x \in$ Ker $(P)$, então $P x=0$ e portanto

$$
\text { CI } I-P X_{x}=x-P x=x
$$

ou seja $x \in I m(I-P)$, tem-se que:

$\operatorname{Ker}(\mathrm{P}) \leq \operatorname{Im}(\mathrm{I}-\mathrm{P})_{\square}$

b) Sex $E \operatorname{Ker}(I-P)$, então

$$
C I-P 2 x=0 \quad x=P x
$$

- portanto

$$
\operatorname{Kor}(I-P) \leq I m(P)
$$

Agora, se $x \in I m(P$, entäo existe um $y \in C$, tal que $P y=$ x.

Então,

$$
C I-P \partial_{X}=C I-P P_{Y}=P y-P^{2} y=P y-P y=0
$$

E portanto,

$$
\operatorname{Im}(P) \leq K(I-P) \square
$$

TEOREMA 3.2.1.3 se $\mathrm{P}$ E idempotente, então $\mathrm{C}=\mathrm{K}$ (P) Im (P).

Prova:

- axioma $(i)$ certamente satisfeito. Agora para qual quer $x$ $\in C$ pode-se escrever $x=x_{1}+x_{2}$ onde $x_{1}=C I-P \supset x_{2} x_{2}=$ 
$P x, p D i s x=x_{1}+x_{2}=C I-P D x+P x=x-P x+P x=x$. Então $\left.x_{1}=I m C . I-P\right)$ pelo item $(a)$ do Teorema 3.2.1.2,

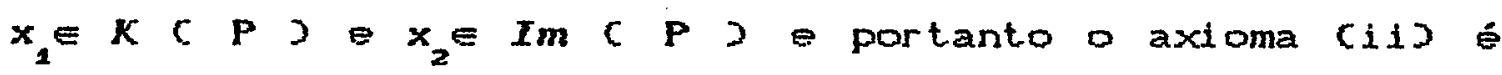
satisfeito. Se $x \in K C P \supset \in x \in I m C P \supset$ então pelo item

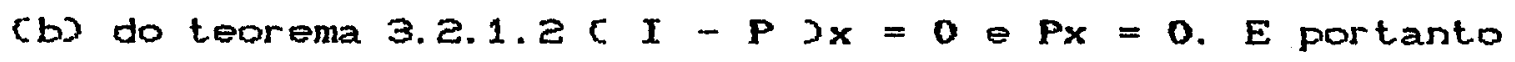
$x=0$ o axioma (iil) é satisfeito $\square$.

DEFIMICĂO 3.2.1.3 Seja $\mathrm{E}$ um espaco linear com produto interno. Para um subespaco $E_{1}$ qualquer, denota-se $E_{1}^{1} 0$ complemento ortogonal de $E_{1}$, então $E=E_{1} \oplus E_{2}^{\perp}$, ou seja todo $x \in E$ pode srer expresso unicamente como $x=x_{1}+x_{2}$, onde $x_{1}$ $E E_{1} e x_{2} \in E_{1}^{1}$. A correspondencia $P: x \rightarrow x_{1}$ é uma transformação linear de E, a qual é chamada projecão ortogonal de $E$ em $E_{1}$.

TEOREKA 3.2.1.4 Se P É um projetor ortogonal de E em $E_{1}$. então (I-P) é um projetor ortogonal de $E$ em $E_{1}^{\perp}$.

Prova: Análoga à do corolário 3.2.1.1.

TEOREMA 3.2.1.5 Seja $\mathrm{P}$ um projetor de E em $\mathrm{E}_{1}$. Entäo $\mathrm{P}^{2}=\mathrm{P}$ - $\mathrm{P}^{\prime}=\mathrm{P}$, onde $\mathrm{P}^{\prime}$ é 0 transposto de $\mathrm{P}$. Reciprocamente qualquer transformacão linear $\mathrm{P}$ com estas propriedades projetor ortogonal em algum subespaco.

Prova:

CIJ Se $P$ é um projetor ortogonal de $E$ em $E_{1}$ então $P^{2}=P$ $\mathbf{P}^{\prime}=\mathbf{P}$. 
A primeira parte pode ser obtida através do teorema 3.2.1.1. Agora com Px $E_{1} \in C I-P D y \in E_{1}^{\perp}, \forall$ $x, y \in E$, tem-se que $\langle(I-P) y, P x\rangle=0 \forall x, y \in E$, ou seja, $\left\langle P^{\prime} C I-P \supset y, x\right\rangle=0 \forall x, y \in E$. Então,

$$
\begin{aligned}
& P^{\prime} C I-P \supset y=0, \forall y \in E \\
& \Rightarrow P^{\prime} \subset I-P J=0 \\
& \Rightarrow P^{\prime}=P^{\prime} P
\end{aligned}
$$

como, $\mathbf{P}=\left(P^{\prime}\right)^{\prime}=\left(P^{\prime} P^{\prime}\right)^{\prime}=P^{\prime} P=P^{\prime}$

portanto $\quad P^{\prime}=P$

CIIJ Se $P=P^{2}=P^{\prime}=P$ então $P$ é um projetor ortogonal.

Seja $E_{2}$ o conjunto de todos os vetores $x_{2}$, tal que $P x=x_{1}$ para algum $x \in E$. Pelo Teorema 3.2 .1 .1 , se $\mathbf{P}^{\mathbf{Z}}=\mathbf{P}$,

$$
\begin{array}{ll}
P x_{1}=x_{1}, & \forall x_{1} \in E_{1} \\
P x_{2}=0, & \forall x_{2}=x-x_{1}
\end{array}
$$

Objetiva-se mostrar que para todo $x \in E$,

$$
x=x_{1}+x_{2},
$$

onde $x_{2} \in E_{1} \in x_{2} \in E_{1}^{\perp}$. Como 
26.

$$
\left\langle P x_{2}, x_{2}\right\rangle=C x^{\prime} x_{2}=x^{\prime} P^{\prime} x_{2}
$$

- por suposicão. $\quad P^{\prime}=P$

$$
\left\langle\mathbf{P x}, \mathbf{x}_{2}\right\rangle=\mathbf{x}^{\prime} \mathbf{P x _ { 2 }}=0, \forall \mathbf{x} \in \mathrm{E}, \quad \forall \mathbf{x}_{2}=x-x_{1}
$$

portanto,

$$
x_{2} \in E_{2}^{\perp}
$$

TEOREMA 3.2.1.6 Seja P um projetor ortogonal de $E$ em $E_{1}$. Entio, $\|$ y $\left\|_{2}=\right\|$ Py \|\|$_{2} \forall$ y $\|$ E, onde \|\|$_{2} \circ a$ norma euclidiana.

Prova:

Tem-se que:

(I) $\left.\left.\|\operatorname{Py}\|\right|_{2} ^{z}\right\rangle=0, \forall y \in E$,

então

$$
\begin{aligned}
& \| P y||_{z}^{2}=\langle P y, P y\rangle=P^{\prime} P^{\prime} P_{y}= \\
& \left.=y^{\prime} P^{2} y=y^{\prime} P y=\langle P y, y\rangle,\right\rangle=0
\end{aligned}
$$

(II) $\| C I-P S||_{2}^{2}>=0, \forall y \in E$, então

$$
\begin{aligned}
& \|C I-P \partial y\|_{z}^{2}=\langle C I-P \partial y, c I-P \partial y\rangle= \\
& =y^{\prime} C I-P J^{\prime} C I-P J y=y^{\prime} C I-P J^{2} y= \\
& =y^{3} C I-F>y=\langle C I-F>y, y\rangle \quad s=0
\end{aligned}
$$

Agora,

$$
\begin{aligned}
& \|y\|_{2}^{2}-\|P y\|_{z}^{2}= \\
& =\langle y, y\rangle-\langle P y, P y\rangle=\text { PI } \\
& =\langle y, y\rangle-\langle P y, y\rangle\rangle\rangle=\mathbb{O}^{\text {(IX) }}
\end{aligned}
$$


e portanto

$$
H \operatorname{Pr}\left\|_{2}<=\right\| \text { r } \|_{2} 0
$$

\subsubsection{PROJETORES ORTOGONAIS E MATRIZES}

A utilizacão dos conceitos de projetores ortogonais no modelo linear sera apresentada neste item. Alguns poucos conceitos serão apresentados sem um maior desenvolvimento de modelos lineares, que serấo detalhados no próximo item para não perder a oportunidade de tirar conclusöes simples e imediatas de definicóes e teoremas apresentados neste item.

DEFI NICÃO 3.2.2.1 Considere a matriz real $A_{m \times n}$ os vetores $x \in \mathbb{R}^{n}$ e $y \in \mathbb{R}^{m}$. Se y é um vetor definido pelo sistema de equacōes

$$
A_{m \times n} x_{n \times 1}=y_{m \times 1}
$$

então y é um vetor do espaco vetorial $\mathrm{E}^{m}$. Diz-se, neste caso, que o vetor $x \in E^{n}$ foi transfomado no vetor $y \in E^{m}$ através da matriz de tranśformacão $\mathrm{A}_{\operatorname{mxn}}$.

$$
\begin{array}{r}
\text { Seja } A_{m \times n} \text { uma matriz que transforma vetores } \\
x_{i} \in \mathbb{R}^{n} \text { vem vetores } y_{j} \in \mathbb{R}^{m} \text {. Então, se para quaisquer dois }
\end{array}
$$


28.

vetores $x_{1} \odot x_{2}$ quaisquer dois escalares reais $c_{1}$ e $c_{2}$, ocorrer sempro.

$$
\left.A C c_{2} x_{1}+c_{2} x_{2}\right)=c_{1}\left(A x_{1}\right)+c_{2}\left(A x_{2}{ }^{2}\right.
$$

a transformacão é dita linear. As transformacões do tipo Ax = y são, al óm de lineares, homogêneas. Posto que $\mathrm{AO}=0$.

Se $A_{n}$ é não singular então $y=A x$ ह́ transformacão singular. Se $B_{n}$ é ortogonal então $y=B x$ dita ortogonal. Em ambos os casos as transformacões são bi jetoras.

TEOREMA 3.2.2.1 As transformacôes ortogonais preservam a distância euclidiana entre vetores.

Prova:

Seja $y=A x, \quad A^{\prime}=A^{-1}$

Uma vez que $\left\|y_{2}-y_{2}\right\|_{2}^{2}=\left\langle\left(y_{1}-y_{2}\right),\left(y_{1}-y_{2}\right\rangle\right\rangle$ então

$$
\begin{gathered}
\left\|y_{1}-y_{2}\right\|_{2}^{2}=\left(y_{1}-y_{2}\right)^{\prime}\left(y_{1}-y_{2}\right)= \\
=\left(A x_{1}-A x_{2}\right) \cdot\left(A x_{1}-A x_{2}\right)= \\
\left.\left.=C x_{1} A^{\prime}-x_{2}^{\prime} A^{\prime}\right)\left(A x_{1}-A x_{2}\right)=\left(x_{1}^{\prime}-x_{2}^{\prime}\right) A \cdot A C x_{1}-x_{2}\right)= \\
\left.\left.\left.=C x_{1}^{\prime}-x_{2}^{\prime}\right)\left(x_{1}-x_{2}\right)=\left(C_{1}-\frac{x_{2}}{2}\right), C_{1}-x_{2}\right)\right\rangle=
\end{gathered}
$$


29.

$=|| x_{1}-x_{2}||_{2}^{2}$

$10 g 0$

$$
\left\|y_{2}-y_{2}\right\|\left\|_{2}=|| x_{1}-x_{2}\right\| \|_{2}
$$

DEFINICÃO 3.2.2.2 Seja $F^{n}$ um espaco vetorial o seja $a$ transformacăo A, que leva os vetores de $V^{n}$ em $E^{m}$.

Entäo $E^{m}=\left[y: A x=y, x \in E^{n}\right]$ é um espaco vetorial.

Seräo formalizadas agora algumas idéi as sobro tipos especiais de transformacópes lineares a que tem particular importância en modelos lineares que são as projeç̃es. Deseja-se inicialmente, projetar um vetor $v \in E$ $\subseteq \mathbb{R}^{m}$ num subespaco $E_{1}$ de $E$.

TEOREMA 3.2.2.2 Seja $u m$ espaco vetorial $E \subseteq \mathbb{R}^{m}$ seja $\left[v_{1}, \ldots, v_{k}\right]$ um conjunto de vetores ortonormais de $\mathrm{E}$. Se $\mathrm{E}_{1}$ - o subespaco de $E$ gerado por $\left[v_{1}, \ldots, v_{k}\right]$ então qualquer vetor $u \in E$ pode ser escrito na forma $u=s_{2}+s_{2}$, com $s_{1} E$ $E_{1}, s_{2} E E_{2} \odot E_{2} \perp E_{2}$ onde

$$
\begin{aligned}
s_{1} & =\left\langle u, v_{1}\right\rangle v_{1}+\ldots+\left\langle u, v_{k}\right\rangle v_{k}= \\
& \left.=c u^{\prime} v_{2}\right\rangle v_{1}+\ldots+\left(u^{\prime} v_{k}\right\rangle v_{k} \\
s_{2} & =u-s_{1} .
\end{aligned}
$$


30.

Neste caso $s_{2}$ é projecão ortogonal de u sobre $E_{1}$ - $s_{2} \in E_{2}$ a direção dessa projecão.

Dados dols vetores reals $u$ $v$ de mesmas

di mensões, então

$$
\langle u, v\rangle v=\langle v, u\rangle v=v\left\langle v, w=v\left\langle v^{\prime}, w\right\rangle=v v^{\prime} u\right.
$$

Então o vetor $s_{2}$ definido no Teorema 3.2.2. pode ser reescito como:

$$
s_{1}=v_{2} v_{2}^{\prime} u+\ldots+v_{k} v_{k}^{\prime} u=C v_{1} v_{1}^{\prime}+\ldots+v_{k} v_{k}^{\prime} 3 u=P u
$$

Por outro lado seja $A=\left[v_{1}, \ldots, v_{k}\right]$ uma matriz cujas colunas são vetores ortonormais $r_{i} \in E, i=1$, $\ldots, k$.

Decorre por simples multiplicacão que $s_{1}=P u$, onde $P=A A^{\prime}$ é uma matriz simétrica idempotente, denominada projetor ortogonal de u no espaco gerado pelas colunas da matriz A ou seja, o espaco gerado por $\left[r_{1}, \ldots, r_{n}\right]$ ou ainda o espaco $E_{1}$, o espaco col una da matriz $A, E_{1}=C(A)$.

Então a transformacão li near $P u=s_{1}$ projeta ortogonalmente os vetores de $E$ no subespaco $E_{i}$. CProjeta ortogonalmente E sobre C(A) .

Além disso, a transformação linear $(I-P) u=$. $s_{2}$, projeta ortogonalmente os vetores de $E$ sobre $C^{\perp}(A)=E_{2}$ - espaco complento ortogonal do espaco col una da matriz A. 
3.2.2.1. A INVERSA DE MOORE-PENROSE

DEFINICÃO 3.2.2.1 Define-se como inversa de Moore-Penrose da matriz A (man) a matriz $X$ que satisfaz as seguintes condicốos:

$$
\begin{aligned}
& \text { (i) } A X A=A \\
& \text { (ii) } X A X=X \\
& \text { (iii) }(A X)=A X \\
& \text { (iv) }(X A)=X A
\end{aligned}
$$

a inversa de Moore-Penrose será denotada por $x^{+}$.

TEOREMA 3.2.2.1.1 Seja A $\in M_{m, n}$. Existe uma úmica matriz $x$ E $M_{n, m}$ que satisfaz as condicōes (i) a (iv) acima.

Prova:

Sejam $x_{2} e x_{2}$ duas matrizes satisfazendo as condlç̋es (i) a (iv) acima.

$$
\begin{aligned}
& \text { Por }(i)=(i \text { ) } \text {, tem-se que: } \\
& x_{i}^{\prime}=x_{i}^{\prime} A^{\prime} x_{i}^{\prime}=A x_{i} x_{i}^{\prime}, i=1,2 \\
& \left.\Rightarrow x_{1}^{\prime}-x_{2}^{\prime}=A x_{1} x_{i}^{\prime}-x_{2} x_{2}^{\prime}\right)
\end{aligned}
$$

- então

$$
\left.\operatorname{Im}\left(x_{1}^{\prime}-x_{2}^{\prime}\right) \in \operatorname{Im} \in A\right)
$$

Utilizando-se as equacóes $(1)$ e $(1)$, tem-so que: 
32.

$$
\begin{gathered}
A^{\prime}=A^{2} x_{i}^{\prime} A^{\prime}=x_{i} A A^{\prime}, i=1,2 \\
\Rightarrow C x_{2}^{\prime}-x_{2} D A A^{\prime}=0 \text { oU } A A^{\prime} C x_{i}^{\prime}-x_{2}^{\prime} D=0
\end{gathered}
$$

- então

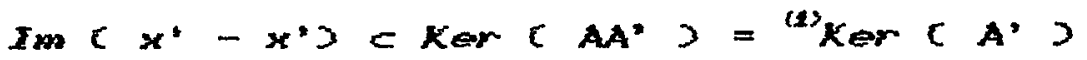

CCA LANCACTER E JOHNSON $\left(1995 \lambda\right.$, seç̃o 5.33. E como Ker $\left.C A^{\prime}\right)$ é Im ( A S Clancaster, secão 5.12, temos que:

$$
x_{1}^{\prime}-x_{2}^{\prime}=0
$$

- portanto $x_{i}^{*}=x_{2}^{\prime}$.

TEOREMA 3.2.2.1.2 SөA $A M_{m, n}$, então:

$$
\begin{aligned}
& \operatorname{Im}(A)+\operatorname{Ker}\left(A^{+}\right)=\mathbb{R}^{m} \\
& \operatorname{Ker}(A)+\operatorname{Im}\left(A^{+}\right)=\mathbb{R}^{n}
\end{aligned}
$$

Prova:

Tem-se que Im $\left(\mathrm{AA}^{+}\right)=\operatorname{Im}(\mathrm{A})$, pois:

(i) se $y=A A^{+} x \Rightarrow y \in I m\left(A A^{+}\right)$

$$
y=A\left(A^{+} x\right) \Rightarrow y \in \operatorname{Im}(A)
$$

então

$$
\begin{aligned}
& \left.\operatorname{Im} \subset \mathrm{AA}^{+} \supset \subset \operatorname{Im} \subset \mathrm{A}\right) \\
& \text { (ii) se } y=A x \Rightarrow y \in I m(A) \\
& \text { - como } A=A A^{+} A \text {, } \\
& y=A A^{+} A x=A A^{+} C A x \supset \Rightarrow y \in I m\left(A A^{+}\right)
\end{aligned}
$$

então

$$
\left.\operatorname{Im}(A) \subset \operatorname{Im} \subset \mathrm{AA}^{+}\right)
$$


33.

$$
\text { e portanto Im }\left(\mathrm{AA}^{+}\right)=\operatorname{Im}(\mathrm{A})
$$

seja $H=A^{+}$, entẫo $A^{+} H=A^{+} A^{+}=A^{+}$

(1)

posto $\left(\mathrm{A}^{+}\right)=$posto $\left(\mathrm{A}^{+} \mathrm{H}\right\rangle\left\langle=\min \left(\right.\right.$ postor $\left.\mathrm{A}^{+}\right)$, posto ( H $\rangle\langle=$ posto $(H)=$

posto $($ H $)=$ postol $\left.\mathrm{AA}^{+}\right)<=\min ($ postor $\mathrm{A})$, postor $\left.\mathrm{A}^{+}\right)$) $<=$ postor $\mathrm{A}^{+} \mathrm{J}$

(1) ORTEGA (1987) SEç̃o 3. 5$)$

e portanto:

$$
\begin{aligned}
& \text { posto } \left.H \supset=\text { postnor } \mathrm{AA}^{+}\right)=\text {posto }\left(\mathrm{A}^{+}\right) \\
& \text {Assim, }
\end{aligned}
$$

$\operatorname{dim}\left(\right.$ Ker $\left.\left.\left.A^{+}\right)=m-\operatorname{postor} A^{+}\right)=m-\operatorname{postoc} \mathrm{AA}^{+}\right)=$ $\operatorname{dim}\left(K_{e} A^{+}\right)$onde $\operatorname{dim}($.$) é a dimensão (*)$ é dado por LANCASTER E JOHNSON (1985), SEç̃̃ 3.8.

Dado que $x \neq 0$, tem-se que $A^{+} x=0, x$ eKer $A^{+}, e$ comose $A^{+} x=0 \Rightarrow A A^{+} x=0, x \in \operatorname{Ker}\left(A^{+}\right) \in \operatorname{Ker}\left(A A^{+}\right)$ Supondo que $A A^{+}=0$, tal que $x \in \operatorname{Ker}\left(\mathrm{AA}^{+}\right)$, então $A^{+} A A^{+} x=0 \Rightarrow A^{+} A A^{+}=A^{+}$, tem-se que $A^{+} x=0$, tal que $x$ $\in \operatorname{Ker}\left(A^{+} \supset\right.$ Então $\operatorname{Ker}\left(A^{+}\right) \in \operatorname{Ker} C A^{+} 3$.

$E$ portanto KerC $\left.A^{+}\right)=\operatorname{KerC} A^{+}$, e pelo Teorema 2 , seção 5.8 LANCASTER E JOHNSON (1985), tem-se que:

$$
\operatorname{KerC} \mathrm{AA}^{+} 2+\operatorname{ImC} \mathrm{AA}^{+} 2=\mathbb{R}^{m} \text {, }
$$

ecomo $\operatorname{Im}\left(\mathrm{AA}^{+}\right)=\operatorname{Im}\left(\mathrm{A}^{2}\right) \operatorname{\operatorname {Ker}}\left(\mathrm{AA}^{+}\right)=\operatorname{Ker}\left(\mathrm{A}^{+}\right)$, tem-se. que:

$$
\operatorname{Kerc} A^{+} 2+\operatorname{ImC} A 2=\mathbb{R}^{n}
$$


- desenvol vendo-se de forma análoga ao anterior, usando a definicão de-inversa de Moore-Penrose, chega-se ao resul tado:

$\operatorname{Ker}\left(A^{+}\right)=\operatorname{Ker}(A) \operatorname{Im}\left(A^{+}\right)=\operatorname{Im}\left(A^{+}\right)$. E portanto:

$$
\operatorname{Kerk} A D+\operatorname{ImC} A^{+} \supset=\mathbb{R}^{n}
$$

TEOREMA 3.2.2.1.3 Para qualquer matriz A $\in M_{m, n}$, tem-se que:

$$
\begin{aligned}
& \operatorname{Ker}\left(\mathrm{A}^{+}\right)=\operatorname{Kar}\left(\mathrm{A}^{\prime}\right) \\
& \operatorname{Im}\left(\mathrm{A}^{+},=\operatorname{Im}\left(\mathrm{A}^{\prime}\right)\right.
\end{aligned}
$$

Prova:

Por definlcão, tem-se que $\mathrm{AA}^{+}$e $\mathrm{A}^{+} \mathrm{A}$ são matrizes simétricas. Como

$$
\begin{aligned}
\left.\left(A A^{+}\right) C A A^{+}\right) & \left.=A C A^{+} A A^{+}\right)=A A^{+}, e \\
C A^{+} A D A^{+} A & \left.=C A^{+} A A^{+}\right) A=A^{+} A
\end{aligned}
$$

$A^{+} A-A^{+}$são matrizes idempotentes a por Lancaster secão 5.1, se uma matriz $B \in M_{m, n}$ idempotente $e$ simétrica, $\operatorname{Im}(\mathrm{B}) \oplus \operatorname{Ker} \mathrm{B})=\mathbb{R}^{n}$.

Então como $\mathrm{AA}^{+} \odot \mathrm{A}^{+} \mathrm{A}$ são matrizes simétricas idempotentes, tem-se:

$$
\begin{aligned}
& \operatorname{Im}\left(\mathrm{AA}^{+}\right) \oplus \operatorname{Ker}\left(\mathrm{AA}^{+}\right)=\mathbb{R}^{m} \\
& \left.\operatorname{Im}\left(\mathrm{A}^{+} \mathrm{A}\right) \oplus \operatorname{Ker} \mathrm{A}^{+} \mathrm{A}\right)=\mathbb{R}^{n}
\end{aligned}
$$

- como na prova do Teorema 3.2.2.1.2 foi visto que a. $\operatorname{Im}\left(\mathrm{AA}^{+}\right)=\operatorname{Im}\left(\mathrm{A}^{2}\right), \operatorname{Ker}\left(\mathrm{AA}^{+}\right)=\operatorname{Ker}\left(\mathrm{A}^{+}, \operatorname{Im}\left(\mathrm{A}^{+} \mathrm{A}^{2}\right)=\right.$ $\operatorname{Im}\left(\mathrm{A}^{+}\right)$e $\operatorname{Ker} \mathrm{A}^{+} \mathrm{A}=\operatorname{Ker}(\mathrm{A})$, tem-se: 
35.

$\left.\operatorname{Im} A \supset \operatorname{Ker} \mathrm{A}^{+}\right)=\mathbb{R}^{m}$

$\operatorname{Tin} A^{+}>\operatorname{Ker}(A)=\mathbb{R}^{n}$

- como por LANCASTER E JOHNSON (1985) secão 5.1 tem-se que:

$$
\begin{aligned}
& I m C A^{+} D \operatorname{KarC} A^{\prime} J=\mathbb{R}^{m} \\
& \operatorname{ImC} A^{+} \supset \operatorname{Ker} A^{\prime} P=\mathbb{R}^{n}
\end{aligned}
$$

então

$$
\begin{aligned}
& \operatorname{xerc} A^{+} 2=\operatorname{xer}\left(A^{\prime}\right), \\
& \operatorname{ImC} A^{+} 2=\operatorname{ImC} A^{\prime} 20 .
\end{aligned}
$$

TEOREMA 3.2.2.1.4 Se A $=M_{m, n}$, então:

(i) $\mathrm{AA}^{+}$é um projetor ortogonal em ImC A $>$na direcão de $\operatorname{Ker}\left(A^{\prime}\right)$.

(ii) $A^{+} A$ é um projetor ortogonal em ImC A's na direcalo de Kerc A.

(iii) I-A A é um projetor ortogonal em KerC A y na direcâo do $\operatorname{Im}$ A

(iv) I - $\mathrm{A}^{+} \mathrm{A}$ é um projetor ortogonal em Kert A I na direcão de $I m C$ A's.

Prova:

(i) Como $\mathrm{AA}^{+}$é simétrica e idempotente, pelo teorema. 3.2.1.5 $\mathrm{AA}^{+}$é um projetor ortogonal. Agora seja $x$ um vetor mx1 qualquer, então se $\mathrm{AA}^{+} \mathrm{x}=\boldsymbol{y}, y \in \operatorname{ImC} \mathrm{AA}^{+}$, e como 
36.

ImC $\mathrm{AA}^{+} \mathrm{y}$ Kerc $\mathrm{AA}^{+} 2=\mathbb{R}^{m}, \mathrm{AA}^{+}$um projetor ortogonal em Im $\mathrm{AA}^{+}$) na direção de KerC $\mathrm{AA}^{+} \mathrm{J}$, e como pelo teorema 3.2.2.1.2 $\left.\operatorname{KerC} \mathrm{AA}^{+},=\operatorname{KerC} \mathrm{A}^{+},=\operatorname{ImC} \mathrm{AA}^{+},=\operatorname{ImC} \mathrm{A}\right)$, pelo teorema 3.2.2.1.3 KerC $A^{+}$, obtém-se (i).

(ii) Análoga à $(i)$.

(iii) Tem-se que:

(a) $\left.\left(I-A A^{+}\right)=\left(I-A A^{+3}\right)=C I-A A^{+}\right)$, pOis $A A^{+}$ simétrica.

(b) $\left.\left.\left.\left.C I-A A^{+}\right) C I-A A^{+}\right)=I-A A^{+}-A A^{+}+C A A^{+}\right) C A A^{+}\right)=$ $=I-\mathrm{AA}^{+}$pois $\mathrm{AA}^{+}$idempotente.

Portanto por $(a)$ e (b) tem-se que I - $\mathrm{AA}^{+}$ um projetor ortogonal em Im A $>$ na direcão de Kerc A' 2 , seja $x=x_{2}+x_{2}$, onde $x_{2} \in I m C A \supset$ P $x_{2} \in \operatorname{Ker} A^{\prime} \supset$.

Então:

$$
\begin{gathered}
{A A^{+} x}^{+} x_{1}, \\
\left.C I-A^{+}\right) x=x_{-}-A^{+} x= \\
=x_{1}+x_{2}-x_{1}=x_{2}
\end{gathered}
$$

- portanto I - $\mathrm{AA}^{+}$é um projetor ortogonal em Kerc $\mathrm{A}^{\prime}>$ na direcão de $\operatorname{ImC}$ A .

(iv) Análoga à (iii).

TEOREMA 3.2.2.1.5 Seja $\mathrm{X} \in M_{m, n} \in \mathrm{X}=$ USV $a$ decomposicão por valores singulares da matriz X. Supondo que $X$ tem posto. $r$ então:

$$
x=U S v^{\prime}
$$




$$
X=\left[\begin{array}{lll}
u_{1} & u_{2}
\end{array}\right] \quad\left[\begin{array}{rr}
S_{1} & 0 \\
0 & 0
\end{array}\right] \quad\left[\begin{array}{l}
v_{1} \\
v_{2} \\
2
\end{array}\right]
$$

onde $U_{1} \in M_{m, r}, \quad U_{2} \in M_{m, m-r}, \quad S_{1} \in M_{r, r}, \quad V_{1}^{\prime} \in M_{r, r} e$ $v_{z} \in M_{n-r, n}$

tem-se que:

$$
x^{+}=v_{1} s_{1}^{-1} v_{1}^{\prime} \text { é a inversa de Moore- Penrose de } x .
$$

Prova:

como $x$ tem posto $r$ :

$$
X=U S V^{\prime}=U_{2} S_{2} V_{i}^{\prime}
$$

Pela definicão de inversa de Moore-Penrose, $x^{+}$é tal matriz, se ela satisfizer as condlcóes (i) a (iv). Supondo então que $x^{+}=v S^{-1} u^{\prime}$ é a inversa de Moore-Penrose de $X$ é necessário a verificacão das condicões:

(i) $x x^{+} x=x$

$$
\begin{aligned}
& \text { tem-se que: } \\
& x x^{+} x=u_{1} s_{1} v_{2}^{-} v_{1} s_{1}^{-1} u_{2} u_{1} s_{1} v_{1}=u_{1} s_{1} s_{1}^{-1} s_{1} v_{2}=u_{1} s_{1} v_{1}=x
\end{aligned}
$$

As demais condicóes são verificadas do modo análogo à verificacão da condiçăo (i). 
38.

\subsection{MODELO LINEAR}

\section{3. 1. O FROBLEMA DE MINIMOS QUADRADOS}

$$
\text { o problema do ajuste por quadrados mínimos }
$$
pode ser expresso da seguinte maneira:

DEFINICÃO 3.3.1.1 Dada uma matriz real $A_{m \times n}$ onde $m \geq n$, um vetor real $b$ de tamanho $m$, encontrar um vetor $x^{0}$ de tamanho n, tal que:

$$
\left\|A x^{0}-b\right\|_{z}^{m i n} x \in \mathbb{R}^{n}\|A x-b\|_{z}
$$

Define-se o vetor $x$ como:

$$
x=\left[x:\|A x-b\|_{z}<=\|A z-b\|_{z}, \forall z \in \mathbb{R}^{n}\right]
$$

(i) Se $x \in X$ então $A^{\prime} C A x-b J=0$, ou seja o residuo $r=$ Ax - b ortogonal as colunas de A CrEImC A $د^{\perp}$.

Prova:

Seja $x \in X$ eseja $w=A^{\prime} C A x-b \supset$. Para tado $\alpha \in \mathbb{R}$ tem-se:

$$
\|A x-b \mid\|_{2}^{2}<=\|A C x+a w 3-b\|_{2}^{2}
$$

assim:

$$
\begin{aligned}
& \|A C x+a w 3-b \mid\|_{2}^{2}= \\
& \left.\left.=(C A x+a A w)^{\prime}-b^{\prime} \operatorname{scc} A x+a A w\right)-b\right)= \\
& =\left[A \times+\alpha A w J^{\prime}(A x+\alpha A w)-C A x+\alpha A w\right)^{\prime} b- \\
& -b^{\prime}(A x+a A w)+b^{\prime} b=
\end{aligned}
$$


$=\|A x-b\|_{2}^{2}+\alpha^{2}\|A w\|_{2}^{2}+2 a C A x J^{\prime C} A x$ ? $-2 a b^{\prime} C$ Aw $=\|A x-b\|_{2}^{2}+a^{2}\|A w\|\left\|_{2}^{2}+2 a\right\| w \|_{z}^{2}=$

$=\|A x-b\|_{2}^{2}+a \operatorname{ca}\|A w\|_{2}^{2}+2\|w\|_{2}^{2}$ - portanto se $w 0$, há uma contradicão para a negativo pequeno. ${ }^{\circ}$

Ciil $\mathrm{X}$ é convexo e tem um único elemento de norma minima $x^{0}$.

$$
\left\|x^{0}\right\|_{2}<\|x\|_{2} \quad \forall x \in x-x^{0}
$$

Inicialmente será provado que $X$ tem um único elemento de norma minima $x^{0}$. O seguinte teorema será utilizado nesta demonstração.

TEOREMA 3.3.1.1 SE A é uma matriz mxn e b e Im $($ A ). então a equação línear $A x=b$ tem uma única solucão $x^{D} \mathrm{em}$ Kerl A $\mathrm{I}^{\perp}$, e qualquer solucão pode ser escrita como $x^{0}+y$, onde $y \in \operatorname{Ker}(A)$.

Prova:

Seja $A: R \rightarrow S$ a equacão linear:

$$
A x=b \quad(I)
$$

para um dado $b \in S$.

Esta equaçao pode ter uma solucão se e somente se, $b \in \operatorname{Im}(A)$. Então se b $\in \operatorname{Im}(A)$, supondo que 
$x^{D}$ seja uma sol ucão. Entấ $x^{D}+y$ te tambóm uma sol uбăo para gualquer $y \in \operatorname{kerC} A$, uma vez que:

$$
\left.A C x^{D}+y\right)=A x^{D}=b
$$

Em geral, qual quer uma das infinitas sol ucõos en (I), pode ter a mesma regra quo $x^{0}$. No entanto, se $x^{0}$ ह restrita a Kerc A $2^{\perp}$ então elo único. Para isto, sejam $x_{1}^{0}$ - $x_{2}^{0}$ duas sol uct̃es quaisquer de $(I), e s e j a$

$$
x_{i}^{c}=u_{i}+v_{i} \quad, i=1,2
$$

a decomposicáo de $x_{i}^{r}$ nas partes $u_{i}$ em kerk $A 3=v_{i}$ em $\operatorname{ker}(A)^{\perp}$.

Entãธ:

$$
A x_{i}^{c}=A v_{i}=b
$$

tal que,

$$
\left.A C r_{1}-r_{2}\right)=0
$$

então $v_{1}^{-} v_{2}$ está no kerc A 2 no kerc A $\nu^{\perp}$, e portanto ele deve ser 0 . Então $r_{2}=r_{2}$, e ficou comprovado que o componente em $\operatorname{ker} A S^{\perp}$ de qualquer solucão é único.

Seja então $x^{0} \in \operatorname{KarC} A \rho^{\perp}$. Entăo $x^{0}$ é único. Seja $x=x^{0}+y$, qual quer outra solucão. Entăo 


$$
\begin{gathered}
\left\|x^{0}+y\right\|_{2}=\left\|x^{0}\right\|_{2}+\|y\|_{2} \\
\left\|x^{0}\right\|_{2}<=\left\|x^{0}+y\right\|_{2}
\end{gathered}
$$

e portanto:

$$
\left\|x^{0}\right\|_{2}<\|x\|_{2}, \forall x \in x-x^{D}
$$

Será provado agora que $X$ é convexo.

Dado $x_{1} \odot x_{2} \in X$, deseja-se mostrar que:

$$
x=a x_{1}+c 1-\infty x_{2} \in X, \forall a \in[0,1]
$$

Seja $x^{0}$ o único elemento de norma minima de $x$. Então $x_{i}+$ $y_{i, i}=1,2$, onde $y_{i} \in \operatorname{Kerl} A$. Então

$$
\|A x-b\|_{2}=\left\|A C a x_{1}+C 1-a x_{2}-b\right\|_{2}=
$$$$
\left\|a A x^{0}+y_{1} 2+\left(1-\infty A C x^{0}+y_{2}-b\right)\right\|_{2}=
$$

$$
=\left\|A x^{D}\right\|_{2}
$$

e portanto $\|A x-b\|_{z} \equiv x$. D

\subsubsection{A SOLUC̆ÃO POR EQUACÕES NORMAIS}

Seja o modelo linear: 
42.

$$
r=x \beta+z
$$

onde

$y$ o vetor $n \times 1$ de variáveis respostas

$X$ é matriz $\Omega \times p$ de variáveis preditoras

$\beta$ o vetor $\mathrm{P} \times 1$ de parâmetros do modelo

* o vetor de erro $n \times 1$, sem qualquer suposicão

adicional sobre sua estrutura estocástica.

Deseja-se encontrar $\beta$ que torne minima a funcão

$$
Q C \beta \partial=\left.\|y-x \beta\|\right|_{2} ^{2}
$$

Tem-se então:

$$
\text { QC } \beta J=y^{\prime} y-2 \beta^{\prime} X^{\prime} y+\beta^{\prime} X^{\prime} x \beta
$$

Derivando $Q C \beta \supset$ em relacão $\beta$ obtém-se:

$$
\frac{d q(\beta)}{d \beta}=-2 X^{\prime} \gamma+2 X^{\prime} X \beta
$$

igualando-se a derivada a zero, encontra-se o chamado sistema de equacónes normais:

$$
x \cdot \hat{x}=x^{\prime} y
$$

Se $X$ tiver posto $P, X^{\prime} X$ definida positiva e portanto não singular, que o caso de modelos de regressão ou de modelos de planejamento com restricóes. Neste caso a 
equacão tem sol ução única:

$$
\left.\beta^{0}=c x \cdot x\right)^{-1} x^{\prime} y
$$

Uma vez que $X \beta^{D}=X C X \times X J^{-1} X^{\prime} y=P y, P$ a transformacão linear representando a projecão ortogonal do espaco Euclidiano n-dimensional $E_{r}$, em $\operatorname{ImC} x$. Da mesma forma, com já visto $(I$ - P J representa a projecăo ortogonal de $E_{n}$ no complemeto ortogonal, ImC $\times د^{\perp}$. Então pode-se

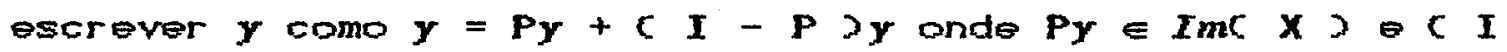
$-P \partial_{y} \in \operatorname{ImC} \times \partial^{1}$.

No entanto, se $x$ nằo tiver posto $p, x^{\prime} x$ tambēm não terá, a equação normal não poderá ser resolvida da mesma forma, uma vez que $X ' X$ năo tem inversa $e$ as equaç̃os normais não proporcionarão uma única solucão. Este ó o caso de modelos de planejamento de experimentos sem restricöes e o caso de matrizes mal-condicionadas de regressão, surgindo entäo, o caso de multicolinearidade que será tema de discussão em capítulos posteriores.

\section{3. 2. PROJETORES ORTOEONAIS E O MODELO LIMEAR}

Foi visto em 3.2 .2 que sendo $A=\left[r_{1}, \ldots\right.$. $\mathbf{r}_{k}{ }^{j}$ uma matriz cujas col unas são vetores ortonormais $v_{i} \in V$, $i=-1, \ldots$, kecorre por simples multiplicacão que $s_{1}=$ Pu, onde $P=A^{\prime}$ é uma matriz simétrica idempotente, denominada projetor ortogonal de $u$ no espaco gerado pelas colunas da matriz A ou seja, o espaco gerado por $I_{\mathbf{r}_{1}, \ldots}, \ldots$, 
$r_{n}{ }^{3}$ ou ainda o espaco $E_{1}$, o espafo col una da matriz $A . E_{1}=$ CrA.

Então a transformação linear $\mathrm{Pu}=s_{1}$ projeta ortogonalmente os vetores de $V$ no subespaco $E_{1}$. CProjeta ortogonal mente $V$ sobre $C(A)$.

Além disso, a transformąão 1 inear $C I-P J u=$ $s_{2}$, projeta ortogonal mente os vetores de $\boldsymbol{V}$ sobre $C^{\perp} \mathrm{CA}=\mathrm{E}_{2}$ - espaco complento ortogonal do espaco col una da matriz A.

TEOREMA 3.3.2.1 Seja $E \subseteq \mathbb{R}^{m}$ tal que $\mathrm{E}=\mathrm{CCA} \oplus \mathrm{C}^{1}(\mathrm{~A})$. Então a matriz que projeta ortogonalmente o espaco E sobre CCA na direcáo de $C^{-1}(\mathrm{~A})$ \& dada por $\mathrm{P}=\mathrm{X \textrm {X } ^ { + }}$, onde $\mathrm{X}^{+}$\& a inversa Eeneralizada de Moore-Penrose. De modo análogo (I - P) é a matriz que projeta ortogonalmente $v$ sobre $C^{1} \mathrm{CA}$ na direcáa $d e \operatorname{CA}$.

Desta forma a aplicacão de projetores em modelo lineares é i medi ata:

(i) $\ddot{\mathbf{y}}=\mathbf{P} \mathbf{y}=\mathbf{X} \mathbf{x}^{+} \mathbf{y}=\mathbf{x} \theta^{\circ}$, onde $\theta^{\circ} \dot{e}$ qual quer sol ucão das equacões normais $X^{\prime} X \theta=X^{\prime} y$, $\theta$ a aproximacão de minimos quadrados para $y \in \mathbb{R}^{m}$.

(ii) $\hat{\varepsilon}=C I-P S y=y-P y=y-\hat{y}$ e orro de ajustamento devido à aproximacão de mínimos quadrados para o sistema inconsistente $x \theta=y, y \in \mathbb{R}^{m}$. 
45.

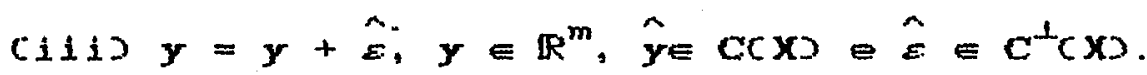

TEOREMA 3.3.2.2 Seja $E \subseteq \mathbb{R}^{3}$ seja E, um subespaco de E. Se $y$ \& um vetor de $E$ então a menor distancia cmelhor aproximacãol de $y$ até $s$ é dada por $\hat{\theta}=y-\hat{y}$, onde $\hat{y} \hat{e} \alpha$ projecão ortogonal de $y$ sobre $E_{1}$.

Prova:

Seja, para alguma matriz $X, E_{1}=\operatorname{Cx} X$ seja $x$ um outro vetor qualquer de $E_{1}$, diferente de $\hat{y}$. Pode-se então escrever:

$$
y-x=c y-\hat{y}+\hat{y}-x y
$$

onde $\hat{x}-\hat{y} \in E_{1}=\cos y=c y-\hat{y} y=\hat{c}=E_{1}^{1}=c^{1} c_{3}$.

Usando o teorema de fitágoras, vem

$$
\|y-x\|_{2}^{2}=\|\hat{\varepsilon} \mid\|_{2}^{2}+\|\hat{y}-x\|_{2}^{2} \quad x
$$

Sendo, por hipótese $y \neq x \in \hat{y} \neq x$, temos que todos os termos de (*) săo estritamente positivos, donde

$$
|| y-x||_{2}^{2}>\|\left.\right|^{m}=||_{2}^{2}
$$


46.

ou equi valentemente $|y-x| \|_{z}>\hat{\varepsilon}$, ou ainda

$$
|| x-y \mid\left\|_{z}>\right\| y-\hat{y}\|\|_{z} \text { a. }
$$

Observa-se então que $\hat{\varepsilon}=y-\hat{y}=y-P y$, onde $y \in E, \hat{Y}=P Y \in E_{1}=C(X) \Leftrightarrow P=X X^{+}$. Então a monor distância (melhor aproximacão) de $y \in E$ ate $E_{1}$ b dada pelo erro devido à aproximacão de minimos quadrados $\hat{\varepsilon}=y-\hat{y}=$ $=y-P y=y-X \theta^{0}, \forall \theta^{0}$ solucão das equacões normais.

TEOREMA 3.3.2.3 Uma condicão necessúria e suficiente para que $\theta^{D}$ seja soluçấo aproximada de minimos quadrados para X $\theta$ $=y$ inconsistente $\ddot{\theta}$. que $\hat{y}=X \theta^{0}=P y$ seja a projecão ortogonal de $y$ em CCX.

Prova: Análoga à do Teorema 3.3.2.2

TEOREMA 3.3.2. 4 Dado o sistema inconsistente $y=X \theta$ uma solucấo aproximada qualquer $\theta^{\circ}$, uma condicấo necessária $\theta$ suficiente para que a $S . Q$ erro devido d aproximacão seja minima é que o vetor de erros seja ortogonal ao espaco columa de $x$.

Prova:

$$
\begin{aligned}
\|\hat{\varepsilon}\|_{2}^{2} M I N & \Leftrightarrow x^{\prime} x \theta^{0}=x^{\prime} y \Leftrightarrow x^{\prime}\left(y-x \theta^{0}=0 \Leftrightarrow\right. \\
& \Leftrightarrow x^{\prime}(y-\hat{y})=0 \Leftrightarrow
\end{aligned}
$$


47.

$\Leftrightarrow X \hat{\varepsilon}=0 \Leftrightarrow \hat{\varepsilon}+\operatorname{CrX} \Delta$

TEOREMA 3.3.2.5 Uma condicâo necessária e suficiente para que a S.Q. do erro devido d̀ solucăo aproximada $\theta^{\circ}$, seja minima es $\hat{y}=$ Py.

Prova:

$\|\hat{\varepsilon}\|_{z}^{2} M I N \Leftrightarrow x^{\prime} x \theta^{D}=x^{\prime} y \Leftrightarrow x^{\prime} \hat{y}=x^{\prime} y \Leftrightarrow \hat{y}=x x^{+} y \Leftrightarrow \hat{y}=P y$.

3. 3.3. MODELOS LINEARES E A DVS

Inicialmente será estuda a solução da equacão linear $A x=b$, para então se fazer a leitura de modelos lineares via DVS.

Seja $A \in M_{m, n}, b \in \mathbb{R}^{n}$ considere a equąão linear $A x=b$. No caso em que o posto de A năo é completo, - sistema será indeterminado, com infinitas solucốes. Deseja-se encontrar uma sol ucão $x^{0}$, tal que:

$$
\left\|A x^{D}\right\|\left\|_{2}=\min _{x \in \mathbb{R}^{n}}\right\| A x-b \|_{2}
$$

TEOREMA 3.3.3.1. Se A = USY', é a decomposicäo por valores sineulares de A, então a solução por mínimos quadrados da equação linear $\mathrm{AX}=\mathrm{b}$, e dada por: 
48.

$$
x^{0}=\sum_{i=1}^{r} \frac{\left(u_{i}^{\prime} b\right)}{s_{i}} v_{i}
$$

onde $r$ e posto CA.

Prova:

Temos que:

$\left\|A x-b\left|\|_{z}^{2}=\right| \mid \text { USV'x }-b\right\|_{z}^{2}$

denotando-se $y=v ' x$,

$$
\begin{aligned}
& \|u s y-b\|_{2}^{2}=\|S y-w b\|_{2}^{2}= \\
& \left.=\left(S y-u^{\prime} b\right)^{\prime} C S y-u^{\prime} b\right)= \\
& r n \\
& \left.=\Sigma C s_{i} y_{i}-u_{i}^{\prime} b\right)^{2}+\Sigma\left[u_{i}^{\prime} b j^{2}\right. \\
& i=1 \quad i=r+1
\end{aligned}
$$

onde $u_{i} \dot{e}$ a $i$-ésima coluna da matriz $U=y_{i}$ é 0 -ésimo elemento do vetor $y$.

Para que esta soma de quadrados seja minimizada com o vetor $y^{0}$ de norma minima, deve-se estabel ecer:

$$
\mathbf{y}^{0}=\mid \begin{array}{ll}
u_{i}^{\prime} \mathbf{b} s_{i} & \operatorname{para} i=1, \ldots, r \\
0 & \operatorname{para} i=r+1, \ldots, n
\end{array}
$$


49.

ou seja,

$$
x^{0}=Y y^{0}=\sum_{i=1}^{r} y_{i} v_{i}=\sum_{i=1}^{r} \frac{u_{i}^{\prime} b}{s_{i}} v_{i}
$$

onde $v_{i}$ é a $i$-ésima coluna de $v$. $^{\square}$

Consider anddo agora o modelo linear

$$
Y=X \beta+\varepsilon
$$

com as condicües de G-M em $\approx$. Seja

$$
X=U S V^{\prime}=U_{1} S_{1} V_{1}^{\prime}
$$

a decomposicăo en valores singulares da matriz $X$.

- problema da aproximacăo consiste em calcular algum $\beta$ que minimize a norma Euclidiara de $\boldsymbol{r}-\mathbf{X} \beta$, Tem-รe então:

$$
\begin{aligned}
& \|y-x \beta\|_{z}^{2}=\left\|y-u S v^{\prime} \beta\right\|_{z}^{2}=\left\|u^{\prime} y-S v^{\prime} \beta\right\|_{z}^{2}= \\
& =\int\left[\begin{array}{c}
v_{2}^{\prime} y \\
v_{2}^{\prime} y
\end{array}\right]-\left(\begin{array}{c}
s_{1} v_{1}^{\prime} \beta \\
s_{2} v_{2}^{\prime} \beta
\end{array}\right] \|_{2}^{2}= \\
& =\left\|w_{1}^{y}-S_{1} v_{1}^{\prime} \beta \mid\right\|_{2}^{2}+\left\|w_{2}^{y} y\right\|_{2}^{2}
\end{aligned}
$$

'Foi usado o fato de a norma Euclideana ser invariante sob transformacốs or togonais. 
o minimo é, então, obti do tomando-se

$$
S_{1} V_{1} \hat{\beta}=v_{2} Y \text {, }
$$

ou $s e j 2$,

$$
\hat{\beta}=Y_{1} S_{1}^{-1} U_{1}^{\prime} Y=x^{+} Y
$$

Outras quantidades de interesse podem ser deter mi nadas:

Valor ajustado. $\hat{y}=\hat{X \beta}=u_{1} S_{1} v_{1}^{\prime} v_{1} S_{1}^{-1} v_{1}^{\prime} Y=u_{1} u_{1}^{\prime} y$

Vetor de residuos. $\left.\hat{\varepsilon}=y-\hat{y}=c I-u_{1} v_{1}^{\prime}\right) \quad y=u_{2} u_{2}^{\prime} y$

Projetor or togonal de $y$ em $C(x) \cdot P_{X}=u_{1} u_{2}^{\prime}$

Projetor ortogonal de $\mathbf{Y} \in \mathbf{C}\left(\mathbf{X}^{\prime}\right) \mathrm{P}_{X^{\prime}}=\mathbf{Y}_{1} \mathbf{Y}_{1}^{\prime}$

Projetor ortogonal de $y$ em $C^{\perp}(x) \cdot P_{X}^{\perp}=I-u_{1} u_{1}^{\prime}=u_{z} u_{z}^{\prime}$

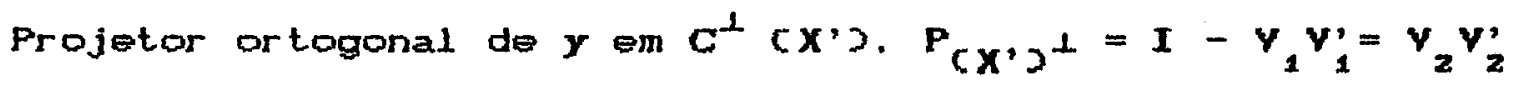

Pode-se verificar en cada projetor a simetria idempotência de cada matriz. Além destas pode-se determinar através da DVS as expressões de somas de quadrados e expressões para as variâncias dos estimadores dos $\beta_{i} \theta e^{-}$ $\hat{y}$, que serão mostradas quando da sua utilizacão no estudo de esti mação viciada. 
51.

\section{4. ESTIMABILIDADE}

\section{4. 1. ESTIMABTLIDADE NO MODELO DE GAUSS MARKOV}

DEFINICÃO 3.4.1.1 O modelo linear $y=x \theta+\varepsilon$, onde:

$r_{n \times 1}$ - um vetor de realizacôos de variáveis aleatórias,

$x_{n \times p}=$ uma matriz conhecida, de posto $r \leq m i n c n$, p

$\theta_{p \times 1}$ é um vetor de parámetros desconhecidos, e

$E_{n \times 1}$ • um vetor de variáveis aleatórias não observáveis, tal que $\left.z \approx C 0, I d^{2}\right)$, definido como o modelo linear de Gauss-Markov CG.M..

Desta forma, EX $y \supset=E(X \theta+\varepsilon)=x \theta+0=$

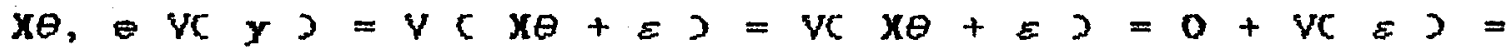
$I \sigma^{2}$. E portanto $y \approx C x \theta, I \sigma^{2}$. A matriz de covariâncias pode, no entanto, assumir caracterizacöes mais complexas

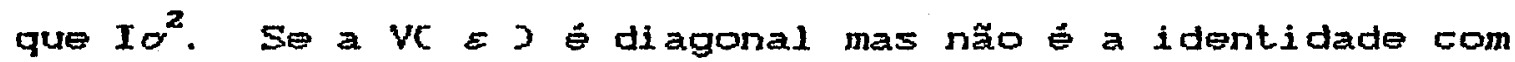
$\sigma^{2}$ em evidência $\theta$ as demais prossuposicốs permanecem inalteradas então o modelo $\&$ referido como modelo linear ponderado de Gauss-Markov. $E$ se a matriz de covariancias tem estrutura mais geral que as formas diagonais anteriores, então o modelo é referido como modelo linear generalizado de Gauss-Markov.

Dado $y=x \theta+E$ CG.M. S, se $x$ tem posto col una 
completo como en geral bcorre em problemas de regressão, a menos de colinearidades, então $X ' X$ é positiva definida portanto não sigular, neste caso, a solucão única do sistema, dada por:

$$
\hat{\theta}=(x \cdot x)^{-1} x^{\prime} y
$$

Além disto $\hat{\theta}$ estimador não viciado para $\theta$.

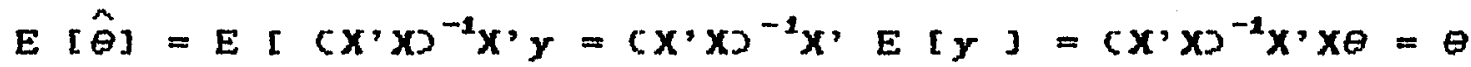

Assim, pode-se dizer que se $x$ tem posto coluna completo, a solucão única de mínimos quadrados de $\hat{\theta}$ - O estimador de mínimos quadrados para $\theta$.

A matriz de variâncias e covariancias pode ser abtida por:

$$
\begin{aligned}
& \left.v[\hat{\theta}]=V[c x \cdot x)^{-1} x^{\prime} y\right]=c x^{\prime} x>^{-1} x \cdot v[y] x(x \times x)^{-1}= \\
& \left.=C X \times D^{-1} X \cdot I \sigma^{2} \times C X \times D^{-1}=C X \times\right)^{-1} \sigma^{2}
\end{aligned}
$$

No caso em que $x$ não tem posto coluna completo, como no caso de delineamentos experimentais, a menos de restricóes ou parametrizaḉ̃es ou no caso de multicolinearidade en regressăo, $\quad C X \times S^{-1}$ năo existe 0 siștema de equacóos normais $\dot{e}$ indeterminado. Neste caso a sol uç̃o não é um estimador não viciado de $\theta$.

Agora, serão formalizados alguns conceitos básicos sobre estimacão em modelos lineares: 
53.

DEFINICÃO 3.4.1.2 (RAO, 1945$)$ Uma funcão tinear paramétrica, $\lambda^{\prime} \theta$ é dita estimátrel no modelo $y=x \theta+\varepsilon$, Q.M., se e somente se, existe uma combinacäo linear das observaçöes a'y, tal que $E\left[a^{\prime} y\right]=\lambda^{\prime} \theta$.

Do ponto de vista prático, esta defincão bem pouco operacional pois depende da dimensão do vetor $y$ das observacóes.

TEOREMA 3.4.1.1 (RAO, 1945$)$ Uma condicão necessária e suficiente para que a funcăo paramétrica $\lambda^{\prime} \theta$ seja estimável no modelo $y=x \theta+E$ (G.M.) $\lambda \in$ C(X').

Prova:

$\left.C \Rightarrow \lambda \lambda \in \operatorname{CXX}^{\prime}\right) \Rightarrow \lambda^{\prime} \theta$ é estimável.

$$
\lambda \in C\left(x^{\prime}\right) \Rightarrow \exists a: x^{\prime} a=\lambda \Rightarrow \lambda^{\prime}=a^{\prime} x
$$

pós-multiplicando-se por $\theta$ obtóm-se.

$\lambda^{\prime} \theta=a^{\prime} \times \theta \Rightarrow \lambda^{\prime} \theta=a^{\prime} E[y] \Rightarrow \lambda^{\prime} \theta=E\left[a^{\prime} y\right] \Rightarrow \lambda^{\prime} \theta$ é estimável.

$c \Leftarrow 2 \lambda^{\prime} \theta$ é estimável $\Rightarrow \lambda \in \operatorname{CxX}^{\prime}$

$$
\lambda \cdot \theta \text { estimável } \Rightarrow \lambda \in C(X ')
$$

$\lambda^{\prime} \theta$ estimável $\Rightarrow \exists a:$ a $\left[a^{\prime} y\right]=\lambda^{\prime} \theta \Rightarrow \alpha^{\prime} \times \theta=\lambda^{\prime} \theta \Rightarrow \lambda \in C\left(X^{\prime}\right)$ 
54.

$\checkmark \theta$

COROLÁrIo 3.4.1.1 Cada condicăo dada a seguir é necessária - suficiente para que $\lambda^{\prime} \theta$ seja estimável no G.M.

(i) $r[x]=r[x, \lambda]$

(ii) $r\left[x^{\prime} x\right]=r[x \cdot x \mid \lambda]$

DEFINICÃo 3.4.1.3 Dada a funcăo paramétrica $\lambda^{\prime} \theta$ estimáuel no G.M., então $o$ sistemo consistente $X^{\prime} X_{\rho}=\lambda \dot{\theta}$ definido como sistema de equacôes normais associados.

- sistema de equacöes normais associadas preserva propriedades importantes das equacốs normais, como por exemplo a invariância do $x p^{0}$, $v^{0}$ solucão das equaçóes normais associadas.

DEFINICÃo 3.4.1.4 Dado o modelo de Gausis-Markov, sejam

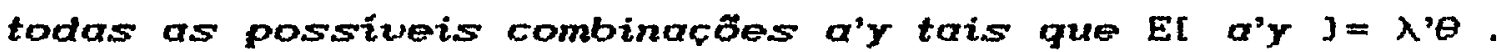
Dentre elas, seja $a^{*} y$. Então $a^{*} y$ é definido como o melhor estimador näo viciado de $\lambda^{\prime} \theta$ se e somente se :

$$
V\left[a^{*} y\right]=\min V\left[a^{\prime} y\right], \forall a^{\prime} y: E\left[a^{\prime} y\right]=\lambda^{\prime} \theta
$$

$$
a^{*} Y \text { é conhecido como "BLUE" de } \lambda \text { ' } \theta \text {. C Best - }
$$

Linear Umbiased Estimator 2. Denota-se igualmente: 
55.

"BLUE" de $\theta$ de $\lambda^{\prime} \theta=\lambda^{\hat{\prime}} \theta$.

TEOREMA 3.4.1.2 Se $\lambda^{\prime} \theta$ E estimáwel no G.M. então seu "BLUE" pode ser obtido de:

$$
\lambda^{\hat{0} \theta}=\rho X^{\prime} y(\text { únicos) }
$$

onde $p$ é qualquer soluct̃o das equaçöes normais associadas.

TEOREMA 3.4.1.3 CGAUSS-MARKOVD Se $\lambda^{\prime} \theta$ é estimável no modelo $y=x \theta+\Sigma$, entäo $\lambda^{\hat{2} \theta}=\lambda^{\prime} \theta^{0}$, qualquer $\theta^{0}$ solucâo das equaçöes normais.

3. 4. 2. LEI TURA PELA DVS

Seja o modelo linear $S M$

$$
\mathbf{y}=\mathbf{x} \theta+\varepsilon
$$

que pode ser escrito como $y=U S V^{3}+\varepsilon$, que pré-multiplicado por $U^{\prime}$, torna-se

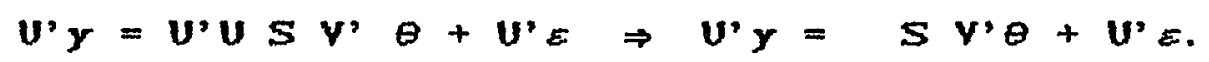

essa expressão pode ser decomposta em

$$
\begin{aligned}
& u_{2}^{\prime} y=S_{1}^{\prime} y_{1}^{\prime}+u_{1}^{\prime} E \\
& u_{2}^{\prime} y=0+u_{2}^{\prime} E
\end{aligned}
$$


Esta forma mostra que apenas funcöes $\lambda^{\prime} \theta \operatorname{com} \lambda$ no espaco $G\left(X^{\prime}\right)=\operatorname{CrY} y_{1}$ são identificáveis dos dados. Estas expressöes são chamadas de forma canönica do Modelo Linoar. De acordo com o Teorema de Gauss-Markov, o melhor estimador linear não tendencioso C"BLUE - Eest Iinear unbiased estimator' de $\lambda^{\prime} \theta$ é dado por

$$
\lambda^{\mu} \theta=\lambda \cdot \theta^{D}
$$

onde $\theta^{0}$ \& qual quer solucão do sistema de equacôes normais do modelo linear de Gauss-Markov,

$$
\text { para } \theta^{D}=Y S^{-1} u Y
$$

verifica-se que:

$$
\begin{aligned}
& \text { (1)E[ } \left.\lambda^{\prime} \theta\right]=E\left[\lambda^{\prime} V s^{-1} U^{\prime} y\right] \\
& =\lambda, Y S^{-1} u, E[y] \\
& =\lambda, Y S^{-1} u^{\prime} U S V^{\prime} \theta \\
& =\lambda^{\prime} \vee V^{\prime} \theta=\lambda \cdot \theta \text { cconforme Teorema 3.4.2.1 } \\
& \text { (2) } \operatorname{Var}\left[\lambda^{\prime} \theta\right]=\lambda, \operatorname{Var}\left[\theta^{D}\right] \lambda \\
& =\lambda^{\prime} \operatorname{var}\left[\gamma S^{-1} u, y\right] \lambda \\
& =\lambda, v s^{-1} u^{\prime} \operatorname{Var}\left[y^{\prime} u s v^{\prime} \lambda\right. \text {, }
\end{aligned}
$$

mas Var $[y]=I \sigma^{2}$, então

$$
\operatorname{Var}\left[\lambda^{\prime} \theta\right]=\lambda, Y S^{-1} U^{\prime} I \sigma^{2} u S V^{\prime} \lambda
$$


57.

assim,

$$
\operatorname{Var}[\lambda \cdot \theta]=\lambda \cdot v s^{-2} v^{\prime} \lambda \sigma^{2}
$$

Visto que $\lambda^{\prime} \theta$ estimável se $\lambda \in C\left(X X^{\prime}\right)$, o espaco linha da matriz $x$ é não estimável caso contrário, surge o problema de determinar na prática se $\lambda^{\prime} \theta$ é estimável para um certo $\lambda$.

A DVS fornece modos convenientes de se verificar a est i mabil i dade:

\section{(a) CARVALHO FILHO E IEMMA (1990)}

TEOREMA 3.4.2.1 A funcäo $\lambda^{\prime} \theta$ é estimável no modelo linear de Gauss-Markou se e somente se $\lambda^{\prime} Y_{2} Y_{2}^{\prime}=\lambda$ '.

Prova:

$C \Rightarrow$ Seja $\lambda^{\prime} \theta$ estimável. Então existe uma funcão linear de observacöes a'y tal que EC $a^{\prime} y>=\lambda^{\prime} \theta$, ou seja

$$
E\left(\alpha^{\prime} y\right)=\alpha^{\prime} E\left(y>=\alpha^{\prime} X \theta=\lambda^{\prime} \theta\right.
$$

Substitituindo $X$ pel a sua Dis tem-se que:

$$
a^{\prime} U_{2} S_{1} v_{1}^{\prime}=\lambda^{\prime}, \forall \theta
$$

Pás-mul tiplicando esta expressão por $V_{i} V_{i}^{\prime}$, tem-se

$$
a^{\prime} U_{1} S_{1} Y_{1}^{\prime} Y_{1} V_{1}^{\prime}=\lambda V_{1}^{\prime} Y_{1}^{\prime}
$$

Simplificando-se o primeiro termo, obtém-se

$$
a^{\prime} U_{1} S_{1} Y_{1}^{\prime}=\lambda \cdot Y_{1}^{Y_{1}^{\prime}}
$$


58.

resul tando entăo em $\lambda^{\prime} Y_{1}^{Y_{1}^{\prime}}=\lambda$.

$\Leftrightarrow \Leftrightarrow \lambda_{2}^{\prime} V_{2}^{\prime}=\lambda$

pós-multiplicando por $\theta$ tem-se

$$
\lambda \cdot \theta=\lambda \cdot \gamma_{2} V_{1}^{\prime} \theta
$$

de $\theta^{0}=v_{1} S_{1}^{-1} v_{1}, y$, obtém-se que

$$
\left.\left.E\left(\theta^{0}\right)=E C Y_{i} S_{1}^{-1} u_{1} y\right)=v_{1} S_{1}^{-1} u_{1} E C y\right) .
$$

Mas EC $y \supset=x \theta=v_{1} S_{1} v_{1}^{\prime} \theta$,

então,

$$
E c \theta^{D}=V_{2} S_{1}^{-1} v_{1}^{\prime} u_{1} S_{1} V_{1}^{\prime} \theta=v_{2} v_{1}^{\prime} \theta
$$

Retomando, $\lambda^{\prime} \theta=\lambda \cdot V_{2} v_{2}^{\prime} \theta=\lambda \cdot E \operatorname{Cos}=\lambda \cdot y_{1} S^{-1} U$ ECys tomando-se $\lambda^{*} y_{1} s_{1}^{-1} u_{1}=a^{\prime}, \operatorname{ten}-5 \theta q u \theta$

$$
\lambda^{\prime} \theta=a^{\prime} E(y)=E\left(a^{\prime} y\right)
$$

Desta forma, existe uma funfäo inear das observacóes, a'y, tal que $E\left(a^{\prime} y\right)=\lambda^{\prime} \theta$.

Então de acordo com RAO (1945), $\lambda^{\prime} \theta$ é est.i mável, concluindo a demonstração.

(b) CARVALHO (1982 J Determinada uma precisão para o zero, por exemplo $\varepsilon>0$. Dado um particular $\lambda$, calcula-se - vetor $Y_{z}^{\prime} \lambda$. Se qualquer componente de $V_{2}^{\lambda}$ for maior, em. módulo, que certo valor pré-estabelecido, então $\lambda \cdot \theta$ é declarado não estimável. Uma funcão pode ser estimável 
99.

segundo esse critério $e$ ainda assim ser tal que $y_{\lambda}$ tenha componente não pequeno associado a pequeno $C$ mas não nul o) $s_{i}$, resultando uma variância enorme. Se a variância for muito grande, prefere-se dizer que $\lambda^{\prime} \theta$ é mal-esti mável.

Quando se toma combinacốes lineares, $\alpha^{\prime} y$, que não obedecem os pressupostos do Teorema de Gauss-Markov, trabalha-se com o conceito de quase-estimabilidade, concelto que pode ser compreendido como uma grande proxi mi dade de $\lambda$ do espaco-1inha da matriz $X$ do modelo. 
60.

\section{5. MULTI COLI NEARI DADE}

\subsubsection{REGRESSÃO POR COMPONENTES PRINCIPAIS}

\subsubsection{O NÉTODO}

A técnica de componentes principais se utiliza da aplicacăo da DVS no modelo de regressăo, cuja interpretarão geométrica deixou clara a utilidade em se fazer a troca de $X$ pela sua DVS no sentido de compreender a estrutura da matriz do modelo. No caso do estudo de multicolinearidade sua utilidade ficará mais evidente, como será visto abaixo:

Seja entåo o modelo de regressão $y=X \beta+E$, no qual será introduzida a DVS de $x$.

então

$$
y=U S V^{\prime} \beta+\varepsilon
$$

escrito desta forma o modelo é chamado de "modelo de regressão por componentes principais". A equacão aci ma pode ser escrita como:

$$
y=u \operatorname{cs} \gamma \cdot \beta
$$

onde SV' $\beta$ é uma matriz de ordem $r \times 1$, que é um vetor de $r$ elementos. Esto vetor serä chamado de a. Então: 
B1.

$$
\alpha=S V^{\prime} \beta
$$

e

$$
\mathbf{Y}=\mathbf{u} \alpha+\varepsilon
$$

o vetor $\boldsymbol{Y}$ a matriz $\boldsymbol{U}$ são conhecidos. A solução de minimos quadrados por os coeficientes desconhecidos $\alpha$ são obtidos pelo sistema de equacóos normais:

$$
\tilde{z}=c U^{\prime} U^{-1} u^{\prime} y=U^{\prime} y \text {, uma vez que } U^{\prime} U=I
$$

Esta equacão é facil mente resolvida, uma vez que $\bar{x}$ é simplesmente o produto interno do vetor $y$ pelo $j$-ésimo vetor $u_{j}$.

Segue das últimas relacões que:

$$
\tilde{X}=u^{\prime}\left(v_{\alpha}+\varepsilon=a+u^{\prime} \varepsilon\right.
$$

DU

$$
\alpha-a=u^{\prime} z
$$

Enเล̃o

$$
\left.\left.E C \tilde{\alpha}_{j}-\alpha_{j}\right)=0 \text { ou } E C \tilde{\alpha}_{j}\right]=a_{j}
$$

Ou seja, $\hat{\alpha}_{j} \dot{e}$ estimador não viciado de $\alpha_{j}$. E além disso a variancia de $\bar{\alpha}_{j}$ é dada por:

$\left.\left.\operatorname{var} c \tilde{\alpha}_{j}=E C \boldsymbol{\alpha}_{j}-a_{j}=E C \Sigma u_{i j} u_{i j} \Sigma_{i} \varepsilon_{i}\right)=C \Sigma u_{i j}^{2}\right) \alpha^{2}$ 
Be.

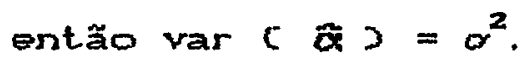

Pode-se mostrar ainda que os $\tilde{j}_{j}$ são mutuamente não correl acionados.

o número de elementos de $\beta$ é, no entanto $p$, enquanto $o$ número de elementos de $\alpha \Leftarrow r$, que pode ser menor que p. Agora, a relacão entre $\beta \in \alpha$ dada anteriormente. também ocorrerá para as estimativas de mínimos quadrados de $\alpha \approx \beta$. Ou seja,

$$
\hat{\alpha}=S V \cdot \hat{\beta}
$$

Na relacăo acima, SV tom dimensão rxp. Entăo, a rolacăo matricial representa $r$ equacbes com $P$ estimativas do parametro $\beta, \hat{\beta}$. Se $r=p C$ o caso de posto completo , a solucão é possivel e única.

Neste caso $Y^{\prime}$ u uma matriz ortogonal pxp.

Então a sol ução será dada por:

$$
\hat{\beta}=V^{-1} S^{-1} \hat{\alpha}=V S^{-1} \hat{\alpha}
$$

Pode-se observar que $S^{-1} \hat{\alpha}$ é um vetor pxi, obtido pela di visão de cada $\hat{\alpha}_{j}$ pelo seu correspondente $s_{j}$.

Um importante uso desta expressão, além de determinar as estimativas de $\beta$ em funcăo de $\hat{\alpha}$, $\dot{0}$ o pronto. cálculo das variâncias de $\ddot{\beta}_{j}$.

Em notacão geral, a última equacão obtida pode ser escrita 
63.

como:

$$
\hat{\beta}_{j}=\sum_{k=1}^{p} v_{j k} \frac{\alpha_{k}}{s_{k}}
$$

Uma vez que os $\hat{\alpha}_{j}$ são mutuamente ortogonais e têm todos a mesma variância $\sigma^{2}$, então:

$$
\operatorname{var}\left(\hat{\beta}_{3}\right)=\left[\sum_{k=1}^{p} \frac{v_{j k}^{2}}{s_{k}^{2}}\right] \sigma^{2} .
$$

- numerador de cada termo são quadrados dos elementos da primeira linha da matriz $Y$, isto $\dot{*}$, sắ valores entre 0 1. Mas os denominadores săo quadrados dos valores singulares. Ocorre que quando um dos $s_{j}$ é considerado pequeno em relação aos outros, ele contribue de forma importante para o aumento do valor da variancia das estimativas dos parâmetros. Ver para maiores informaḉos sobre a lmportância relativa de cada parcela desta variância em (3.5.2.1) número de condição de $x$ e (3.5.2. 2) decomposicão da variância do coeficiente de regressão.

\section{5. 1.2. MULTICOLINEARIDADE E SEUS EFEITOS NA REGRESSÃO}

Os s's são as raízes quadradas dos autovalores da matriz $X \cdot X$. Um $s$ igual a zero, implica em um autovalor igual a zero. Isso por sua vez implica que uma 
B4.

relacão linear existe entre pelo menos alguns dos $p$ $x$-vetores da matriz $X$. Um valor de $s$ muito próximo de zero implica en uma "aproximada" relacão linear entre alguns destes $p$ vetores de $X$.

Literalmente, duas variáveis são colineares so os vetores de dados que as representam estão em uma mesma reta, isto é estão no mesmo subespaco de di mensão um. Mais genericamente, $k$ variáveis são colineares se os vetores que as representam estão em um subespaco de dimensăo menor que $k$, isto é, se um dos vetores combinacão linear dos outros. Na prática, tal "exata colinearidade" raramente ocorre, e isto certamente não dirá necessariamente que um problema de colinearidade existe.

Para efeitos de estimacão estatística, duas variáveis serão consideradas colineares se elas estiverem quase no mesmo subespaco, ou seja, se o ângulo entre elas for poqueno.

Isto equivale a dizer que se o coeficiente de correlacão entre el as for grande existirá "colinearidade". Este conceito pode ser estendido a várias variáveis, dizendo-se que "colinearldade" existe se o coeficiente de correlação múltipla entre elas for alto, quando se faz a regressão de uma variável contra as outras.

Outra forma de se referir à colinearidade,. diz respeito ao "condicionamento" da matriz de dados $x$. Assim, fica claro que a colinearidade tem a 
$B 5$.

ver com as caracteristicas especificas da matriz $X$ e não de aspectos estatisticos do modelo linear $y=X / \beta+$ Então colinearidade estatistico, mas apesar disto têm grande importância na eficácia da estimação de minimos quadrados.

Em regressão por componentes principals, havendo reląão exata entre duas variáveis, então a DVS da matriz X mostrará que un $s_{k}$ será exatamente igual a zero, e desta forma o posto da matriz não será mais $p$ e sim $r=p-1<$ p. Usando a expressão que estima $\alpha$

$$
\hat{\alpha}=u^{\prime} y
$$

pode-se calcular os valores de $\tilde{x}_{k}$. E neste caso o número de valores de a será menor que o número de valores de $\beta$. Se for tentado utilizar a expressão (SY') $\beta=\alpha$ ocorrerá que o número de equacões será menor que o número de parâmetros desconhecidos a serem estimados, e portanto, tem-se um sistema concistente mas indeterminado, e ter-se-ia que expressar $P$ - 1 dos $p$ valores de $\hat{\beta}$ em funcão do outro restante.

Para tratar deste caso MANDEL (1982) sugere que se denote a matriz CSV'S por Z. Assim, 
68.

- particionar $Z$ em $Z_{A} e Z_{B}$, com dimensões $r \times r$ e $\times(p-r)$ respectivamente. Particionando, então o vetor $\beta$ correspondentemente em $r \times 1$ e $(p-r) \times 1$, tem-se

$$
\left(z_{A} z_{B}{ }^{2}\left(\begin{array}{l}
\tilde{\beta}_{A} \\
\tilde{\beta}_{B}
\end{array}\right]=C \approx\right)
$$

que pode ser escrito como $Z_{A} \hat{\beta}_{A}+Z_{B} \hat{\beta}_{B}=C \hat{\alpha}$

pré-multiplicando ambos lados desta expressão por $z_{A}^{-1}$, obtém-se:

$$
\hat{\beta}_{A}+Z_{A}^{-1} Z_{B}^{\beta} \hat{\beta}_{B}=Z_{A}^{-1} \hat{\alpha}
$$

Esta equacão mostra que se um valor para $\hat{\beta}_{\mathrm{z}}$ for arbitrado, $\hat{\beta}_{A}$ será unicamente deter mi nado.

Será agora considerado o caso de predicão. Consirando um novo ponto $x$ para $o$ qual se deseja uma estimativa para $\hat{y}$. Tem-se:

$$
\hat{y}=x \beta
$$

Se for introduzida a particão de $\hat{\beta}$, tal que $\hat{\beta}_{A}$ tenha a dimensão rXi $\mathrm{Cr}$, o posto da matriz $\mathrm{X}$ e for particionado correspondentemente em $x_{A}$, de dimensão $1 \times r$ e $x_{z}$ com di mensด̂อง $1 \times p-r)$.

Então: 


$$
\left.\hat{y}=c x_{A} x_{B}\right] \quad\left[\begin{array}{l}
\hat{\beta}_{A} \\
\hat{F}_{B}
\end{array}\right]
$$

ou

$$
\hat{y}=x_{A} \hat{\beta}_{A}+x_{B} \hat{\beta}_{B}
$$

tomando a expressão desenvol vida para $\hat{\beta}_{A}$ anteriormente, $\theta$ substituindo-a na expressão aci ma, tem-se:

$$
\text { ou } \quad \begin{aligned}
\hat{y} & =x_{A} \cdot\left[Z_{A}^{-1} \tilde{\alpha}-Z_{A}^{-1} Z_{B} \hat{\beta}_{B}\right]+x_{B} \hat{\beta}_{B} \\
\hat{y} & =x_{A}\left(Z_{A}^{-1} \tilde{\alpha}\right)+\left(x_{B}-x_{A} Z_{A}^{-1} Z_{B}\right) \hat{\beta}_{B} \quad(*)
\end{aligned}
$$

Para que a expressão acima faça sentido, deve-se observar que o valor de $\hat{y}$ não muda para qualquer valor arbitrărio de $\hat{\beta}$. Isto implica que

$$
x_{B}-x_{A} z_{A} z_{B}^{-1}=0
$$

- a solucăo para o valor estimado será:

$$
\hat{y}=x_{A}\left(Z_{A}^{-1 \hat{\alpha}}\right)
$$

A expressão em $(*)$ produz duas relacões: a primeira parcela é a solução e a segunda parcela uma condi cão. Mas a solução válida somente quando a condição - satisfeita.

Em resumo: Se $r<p$, não existe sol ucão única para $\hat{y}$ para um ponto $x$, exceto no caso em que este $x$ obedeça a condicão de colinearidade resultante de um valor zero para s. 
68.

\subsubsection{QUASE-MULTI COLI NEARI DADE}

Dada uma matriz $X$ de posto completo mas que tem um autovalor muito pequeno. Neste caso, o lugar geométrico $L_{*}$ discutido na serão anterior de fato não existo, mas todos os pontos da matriz estarăo muito próximos dele. Neste caso o hiper-plano estimado não rotaciona 1 ivremente em torno deste lugar geométrico, e as estimativas de $\hat{y}$ podem ser obtidas para qualquer ponto futuro $x$.

No entanto, pela escolha dos pontos da matriz X, a exata posicâo deste hiper-plano é pobremente conhecida, exceto nas vizinhancas de sua interseccão com a projeção do lugar geométrico $L_{x}$

Considere, então um "novo" ponto $\times(1 \times p)$. Sua representacão através da DVS será.

$$
x=u s v
$$

onde $x$ u são vetores com $p$ elementos. Da expressão acima pode-se derivar

$$
\mathbf{u}=x \mathbf{v} \mathbf{s}^{-1}
$$

uma vez que $\mathbf{v}^{-1}=V^{\prime}$.

Esta relacão voltará a ser discutida abalxo. 
69.

Antes, no entanto, será estudada a predicão de $\hat{y}$ para o - ponto $x$. Expressando este ponto em coordenadas da DVS, tem-se:

$$
\hat{y}=\hat{u a x}
$$

e consequientemente,

$$
\operatorname{var}(\hat{y})=d^{2} \sum_{j} u_{j}^{2}
$$

Esta equacão mostra que um componente grande do vetor $u$ pode fazer com que a variäncia cresca substancialmente.

Será investigado agora em que circunstâncias - vetor u pode ter grandes componentes.

Da relação básica $X$ = USV' obtém-se:

$$
\mathbf{U S}=\mathbf{X V}
$$

$S$ pode ser particionado em dois grupos, $S_{A}$ $S_{B}$, de tal forma que o segundo grupo contenha todos os valores singulares considerados bem menores que os outros.

$$
\text { Neste caso, } S_{B} \text { conterá, por exemplo, } 1
$$
valores. Assim $S_{A}$ é uma matriz diagonal com $p$ - 1 valores. Seja $p-1=t$

Então $S_{A}$ é uma matriz, quadrada, diagonal com dimensão txt e $S_{\mathbf{p}}$ diagonal $1 \times 1$. Particionando $S$ e $V$ em $U S=$ XV, obtém-se: 


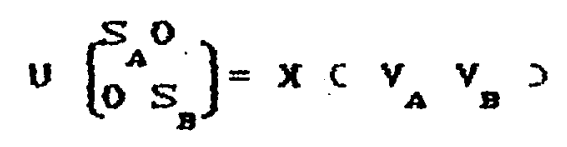

onde $V_{A}$ épxt $V_{B}$ pxl. Esta equacão pode ser escrita como:

$$
\left(U\left[\begin{array}{l}
S_{A} \\
0
\end{array}\right] U\left[\begin{array}{l}
0 \\
S_{B}
\end{array}\right]\right)=C X V_{A} X V_{B} J
$$

Agora, que todos os valores singulares do grupo $B$ săo pequenos, as colunas representadas por UC: ${ }^{2}$ contém elementos que são muito pequenos. 0 mesmo é necessariamente verdade para todos os elementos de $X_{\mathbf{A}}$ Então este fato implica que:

$$
X Y_{\mathbf{s}} \cong 0
$$

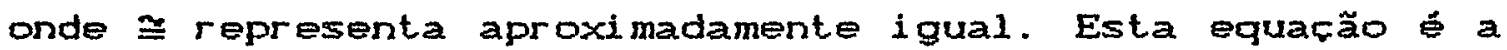
condicão imposta à matriz $X$ pela grandeza dos valores singulares do grupo B, e representa uma ou mais relacónes lineares entre as colunas de $X$.

Retornando agora ao problema de predizer y para um novo ponto $x$, a equaçăo $u=x y S^{-1}$ pode ser reescrita como:

$$
U=C X V_{A} \times V_{B}^{-1} S S^{-1}=C x V_{A} \times V_{B}^{-1} S\left[\begin{array}{l}
S_{A}^{-1} \\
0
\end{array}\right.
$$

Os ultimos 1 elementos de $u$ provêm do 
produto

$$
\left[x_{B} 2 C S^{-1}\right\}
$$

Como cada valor sigular em $S_{B}$ é muito pequeno e consequentemente os seus reciprocos muito grandes, estes elementos de u serão muit grandes, causando um variância para $\hat{y}$ muito grande, a menos que $X y_{g} \cong 0$, ou seja, a menos que 0 novo ponto $x$ satisfaça a condicão de quase-colinearidade da matriz $x$. Quanto mais longe estiver - ponto $x$ da equacão da condicão de multicolinearidade, maior será a variância de $y, i s t o$ é mais pobre será a precisão do valor predito. Este é o coracão do problema de colinearidade, quando visto do pondo de vista da utilidade da regressão estmada para propósitos de previsão.

Uma importante observacão deve ser feita neste ponto. Se os valores singulares no grupo B săo muito pequenos, a correspondente porcão da matriz $v, V_{\boldsymbol{~}}$, é conhecida com precisão numérica muito pequena e $X_{\mathbf{Z}} \cong 0$ pode então conter erros de arredondamento muito grandes. Neste caso, é melhor agir como se estes valores fossem exatamente iguais a zero, e expressar a condicão de quase-colinearidade através de $x_{B}-x_{A} Z_{A}^{-1} Z_{B}=0$.

3. 5. 2. DI AGMósTI CO

3.5.2.1. O NÚMERO DE CONDICÃO

o número de condicão é uma medida de 
72.

sensibilidade do vetor solucão $x$ do sistema 1 inear $A x=b$ para pequenas - mudancas de $b$ de A. Seguindo o procedimento de FORSYTHE E MOLER (1987) esta secão será dividida em duas partes, sendo que na primeira parte será suposto que o vetor b esteja sujeito a incerteza e na segunda parto será suposto que a matriz A esteja sujeita à incerteza e assim será visto o efeito desta incerteza, em $b$ em A no vetor de solucão $x$.

(i) Supondo que o vetor b esteja sujeito a uma incerteza. Seja b + $b$ bm vetor "próximo" de b e que AC $x+d b=b+b b$. Como $A x=b, t e m-5 \theta q u \theta a x=A^{-1} b b$ portanto:

$$
\|\delta \times\|<=\left\|A^{-1}\right\|\|\delta b\|
$$

e

$$
11 b \|<=11 \text { A } 1111 \times 11
$$

assim,

$$
\begin{aligned}
& \|s \times\|\|b\|<=\|A\|\left\|A^{-1}\right\|\|x\|\|b\| \\
& \frac{\|\delta \times\|}{\|\times\|}<=\|A\|\|=11\| \frac{\|b\|}{\|b\|}
\end{aligned}
$$

Define-se como número de condicão de uma matriz não singular $A$ o nưmero| $|A|\left\|\mid A^{-1}\right\|=k \quad A$, อกเล็ั:

$$
\frac{\|\delta \times\|}{\|\times\|},<=k c A>\frac{\|s b\|}{\|b\|}
$$


73.

onde $\frac{\|\delta b\|}{\|b\|}$ pode ser interpretado como a medida de incerteza relativa no vetor $b=\frac{\|\delta \times\|}{\|\times\|}$ pode ser interpretado como a medida de incerteza relativa no vetor $x$ devido à incerteza em b. A equacão (3.5.2.1.1) mostra que - número de condicão kCA fornece um limite para a medida de incerteza relativa no vetor de solucão x c ||$\delta x|| / \|$ * Il J dada a medida de incerteza de b.

(i1) Supondo que a matriz A esteja sujeita à Incerteza. Então:

$$
x+\delta x=[A+\delta A)^{-1} b
$$

e

$$
\begin{aligned}
& \left.\delta x=C A+\delta A)^{-1} b-A^{-1} b=[C A+\delta A)^{-1}-A^{-1}\right] b= \\
& =\left[A^{-1} A\left[A+\delta A J^{-1}-A^{-1}[A+\delta A] C A+\delta A J^{-1}\right] b=\right. \\
& \left.=\left[A^{-1}\left[A(A+\delta A]^{-1}-C A+\delta A J\right) C A+\delta A\right)^{-1}\right] b= \\
& =-A^{-1} \text { SA } C A+S A S^{-1} B= \\
& =-A^{-1} \& A C x+B \times 3
\end{aligned}
$$

- portanto.

$$
\begin{aligned}
& \|\delta \times\|<=\left\|A^{-1}\right\|\|A\| \frac{\|\delta A\|}{\|A\|}\|x+\delta x\| \\
& \frac{\|\delta \times\|}{\|x+\delta x\|}<=k \text { i }>\frac{\|A\|}{\|\delta A\|}
\end{aligned}
$$


- a incerteza de $x$ em relacão a $x+\delta x$ é limitada pela Incerteza relativa de A multiplicada pelo número de condicão de A.

Assim o número de condicão depende da norma usada, e no caso da norma definida por $\|||$ A $\|||=$ $=\max _{|x|}|=1| A x||$

\|\|$A\|=\| \|$ usv \|\|$=\|s\|=c s_{\max }^{2} x^{2}=s$ max e

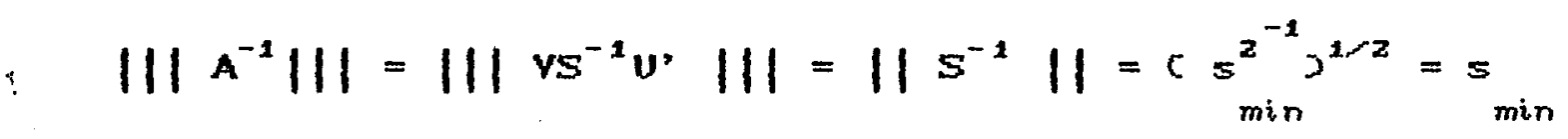
- portanto, o número de condifão kC A $>$ será dado por:

$$
k C A D=\frac{s_{\max }}{s_{\min }}>=1 \text { (3.5.2.1.2) }
$$

- assim, so a matriz X'X singular, o valor do $s_{\min }^{2}=0$ KC $X J \rightarrow \infty$. E se as variáveis preditoras $X=\left[x_{1} \ldots x_{p}\right]$ vistas como vetores forem ortonormais, ou seja, $X \cdot X=I$, então todos os auto-valores de $X^{\prime} X$ serão lguais a um $k C X$ $J=1$. Então, a variacão do número de condicão $e$ de $[1, \infty$ 3, observando-se que quanto maior for o número de condicão kC $X$ 2, mais a matriz $x$ sera mal condicionada.

3.5.2.2. DECOMPOSICÃO DA VARIANCIA DO COEFICIENTE DE REGRESSÃo 
Gada beta estimado pode ser decomposto em olementos da matriz de auto-vetores ortonomais de $X^{\prime} X$ de auto-valores de $X \cdot X$ para uma melhor visão e compreensão sobre a magnitude desta variância.

Cosiderando o modelo de regressăo

$$
y=x \beta+\varepsilon
$$

Seja $\hat{\beta}$ o estimador de minimos quadrados de $\beta$. Então $V(\hat{\beta})$ $=\alpha^{2} \mathrm{C} \times \times 3^{-1}$. Usando a decomposicão em valores singulares da matriz $X$, obtém-se:

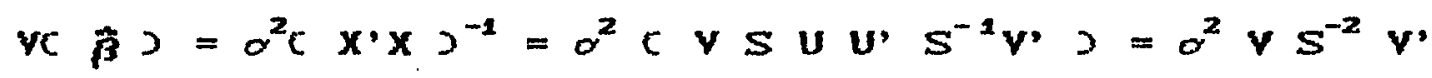

- portanto o k-ésimo componente de $\hat{\boldsymbol{\beta}}$ será:

$$
\text { vc } \tilde{\beta}_{k} \supset=\sigma^{2} \sum_{j} \frac{v_{k j}^{2}}{s_{j}^{2}} \text { (3.5.2.2.1) }
$$

ou seja, VC $\vec{\beta}_{k}$ se decompöe em soma de componentes, onde cada componente $\dot{e}$ associado a um dos $p$ autovalores de $X$ ' $X$. Na equacăo (3.5.2.2.1) mesmo que a matriz $X^{\prime} X$ tenha uma autovalor pequeno em relacăo ao maior autovalor, o que. implica em un valor grande para o número de condicão da matriz, não necessariamente o valor de vC $\vec{\beta}_{k}{ }^{\prime}$ será grande, pois se o valor de $v_{k j}^{2}$ for pequeno ou próximo de $s_{j}^{2}$ esta 
78.

varlância năo será afetada.

-Define-se C BELSLEY, KUH E WELSCH, 1980 ) $k, j$-ésima proporcão da decomposicão da variância $t \pi_{k j}$, como a proporfão da variancia do $k$-ésimo componente da sua decomposicão em (3.5.2. 2.1). Ou seja:

$$
n_{k j}=\frac{\phi_{k j}}{\phi_{k}}, k=1, \ldots, p
$$

onde $\phi_{k j}=\frac{v_{k j}^{2}}{s_{j}^{2}} \quad \phi_{k}=\sum_{j=1}^{p} \phi_{k j}, k=1, \ldots, p$

Então, a proporç̃o da decomposiçăo da variância soră:

$$
\Pi_{j k}=\frac{\phi_{k j}}{\phi_{k}} \quad k, j=1, \ldots, p
$$

Para se ter padróos de comparacão de altas proporcões da decomposicão da variância, a tabela abaixo sumariza as resultados encontrados.

Valor singular

Propor cão da

Associado $\operatorname{var}\left(\hat{\beta}_{1}\right) \quad \operatorname{var}\left(\hat{\beta}_{2}\right) \quad \cdots \quad \operatorname{var}\left(\hat{\beta}_{p}\right)$

$\begin{array}{lllll}S_{1} & \Pi_{21} & \Pi_{12} & \cdots & \Pi_{1 p} \\ S_{2} & \Pi_{21} & \Pi_{22} & \cdots & \Pi_{2 p}\end{array}$



$S$
$\Pi_{\mathrm{p} 1}$
$\Pi_{p 2}$
$\cdots$
$\pi_{\text {pp }}$

$\Pi_{j k}$ usa as informacões da DVS para quase dependência de uma forma que é diretamente aplicável para examinar seus efeitos nas estimativas da regressão.

A concentracão da variância de qualquer coeficiente de regressấ poderá ser associada a problemas de colinearidade se pelo menos duas das variâncias do coeficiente de regressão tenham alta proportăo na decomposicão da variância associada com um dos $s_{i}$, que este esteja associado a um número de condição elevado. BELSLEY, KUH E MELSCH (1980) sugerem que este valor esteja pelo menos entre 30 100. MONTEGOMERY E PECK (1982) sugerem que este número possa ser em torno de 10.

\section{6. ESTI MACÃO VICI ADA}

No caso de quase-colinearidade, foi verificado que a variancia de $\hat{y}$ cresce drasticamente quando os pontos $x$ estâio apreciavel mente removidos do subespaco de $x$ no qual os ponto da matriz de delineamento estão $c$ o subespaco definido pela condi căo de colinearidades.

Esta condicão propicia estimativas mais precisas sacrificando a condi tão de não tendenciosidade do estimador de $\hat{y}$. Este procedimento $\dot{e}$ conhecido como "estimação viciada". Será analisado em detalhes somente um 
78.

dos métodos de estimacão viciada que está associado diretamente com a técnica de regressão por componentes principais. A discussão no entanto servirá para revelar a natureza básica do problema e propor uma solucão.

\section{6.1. AVALI AC̆̃̃O DO ERRO NA ESTIMACÃO VICI ADA}

Seja $x$ uma matriz mal condicionada, ou seja, $x$ E uma matriz com quase-colinearidade em algumas de suas col unas.

Então se $x$ satisfaz a condicão $x y_{n}=0, a$ estimativa de $y$ correspondente a este ponto é dada pelos t primeiros termos de $\hat{y}=\sum_{j} u_{j} a_{j}$ onde

$$
u=x v s^{-1}
$$

Enquanto esta estimativa de $y$ produz a correta solução de minimos quadrados para pontos satisfazendo $x y_{z}=0$, ela não é a solução de mínimos quadrados par pontos $x$ que não satisfacam esta condicão, isto é, para pontos que não estão no subespaco definido pela condiçăo de col i nearidade.

Seră denotada por $\hat{y}$, a expressão

$$
\hat{y}=\sum_{j=1}^{t} u_{j} \alpha_{j}
$$


79.

sem haver a preocupação de que a condicão $x v_{g}=0$ seja satisfeita ou não. A equacão acima fé frequentemente chamada de "equacão de predicão viciada de componentes prineipais". A razão de considerar tal equacão uma estimativa é pela reducão da variância que a acompanha. Tem-se.

$$
\begin{aligned}
& \operatorname{var}(\hat{y})=\operatorname{var}\left(\sum_{j=1}^{p} u_{j} \tilde{\alpha}_{j}\right)=\sigma^{2} \sum_{j=1}^{p} u_{j}^{2} \\
& \operatorname{var}(\tilde{y})=\operatorname{var}\left(\sum_{j=1}^{t} u_{j} \hat{\alpha}_{j}\right)=\sigma^{z^{2}} \sum_{j=1}^{2} u_{j}^{2}
\end{aligned}
$$

Considerando que $p=t+1$, e que os últimos 1 valores acarretarăo em grande aumento da variância das estimativas, deseja-se avaliar qual é o estimador preferivel.

o estimador $\hat{y}$ é năo viciado, enquanto o estimador $\tilde{y}$ um estimador viciado. Tem-se:

$$
E(\hat{y})=y, E E(\tilde{y})=E(y)+\sum_{j=t+1}^{p} u_{j} \alpha_{j}
$$

então:

$$
v_{i c i o}(\tilde{y})=E(\tilde{y})-E(y)=-\sum_{j=1+2}^{p} u_{j} \alpha_{j}
$$

Denotando por EMQ o erro médio quadrático, definido por EMQ = Variância $+(v i c i o)^{2}$, tem-se.

$$
\text { EMQ } \hat{y}^{\hat{y}} \supset=\sigma^{2} \sum_{j=1}^{p} u_{i}^{2}
$$


80.

$$
\text { EMQ } c \ddot{y} J=\sigma^{2} \sum_{j=1}^{t} u_{j}^{2}+c-\sum_{j=1+1}^{p} u_{j} a_{j} j^{2}
$$

Usando $\ddot{y}$ no lugar de $\hat{y}$, se "negocia" a reduçăo da variância pela introducão do $(v i c i o)^{2}$.

Examinando o caso onde $t=p-1$. Então a roducăo na variância será $\alpha^{2} u_{p}^{2} \circ \circ(v i c i o)^{2}=u_{p}^{2} \alpha_{p}^{2}$. Então $\tilde{y}$ terá menor EMQ que $\hat{y}$ se somente se o $(v i c i o)^{2}$ for menor que a reducão da variância, ou seja se

$$
u_{f p}^{2} a_{p}^{2} o^{2} u_{p}^{2} \text { ou } a_{p}^{2}<o^{2}
$$

$$
\text { Infelizmente, } \alpha_{p} e \alpha^{2} \text { são paràmetros }
$$

desconhecidos, para os quais somente estimativas são disponíveis. A estimativa para $\alpha_{p} \dot{e} \hat{\alpha}_{p}$. a estimativa para $\alpha^{2}$ a variancia residual após o ajuste dos $\alpha_{p}$. Tem-se da teoria de mínimos quadrados que:

$$
\hat{\sigma}^{2}=\frac{\sum_{i=1}^{n} c y_{i}-\hat{y}_{i}{ }^{2}}{N-p}
$$

que, quando se utiliza os estimadores $\alpha$, resulta:

$$
\hat{\sigma}^{2}=\frac{\hat{\sum}_{i=1}^{n} c y_{i}-\hat{y}_{i}^{y^{2}}}{N-p}=\frac{\sum_{i=1}^{n} y_{i}^{2}-\sum_{i=1}^{n} \vec{\alpha}_{i}^{2}}{N-p}
$$

Se $\hat{\alpha}_{p}$ é de mesma ordem de magnitude que o 
81 .

então a escolha é de difíil decisão, no entanto, se a magnitude destas medidas forem diferentes o método auxilia na escolha do estimador a ser utilizado. No caso de mesma magnitude das medidas outras suposicôes devem ser feitas, como por excemplo que $a_{p}=0$, e neste caso deve-se utilizar o estimador viciado. Por outro lado a hipótese $\alpha_{p}=0$ pode ser testada na anălise de regresão por componentes principais através do teste "t" de Student, tomando-se:

$$
t=\frac{\hat{\alpha}_{p}-\alpha_{p}}{s_{\alpha_{p}}}=\frac{\hat{\alpha}_{p}}{\hat{\alpha}}
$$

Mas ainda que a hipótese năo possa ser rejeitada năo significa que a escolha do estimador viciado seja a mais apropriada. 
Be.

\subsection{UM EXEMPLO}

\subsubsection{DELIMITACÃO DO PROBLEMA}

A ocorrência de mal condicionamento da matriz de regressão comum em trabal cos não experimentais na área bi omédica. O pesquisador aponta no prontuário dos pacientes todas as informações que possam de alguma forma auxiliá-lo na construção de experiência pessoal para determinar futuros prognósticos, e muitas vezes duas ou mais variáveis explicam o mesmo fenómeno, podendo acarretar em mul ti colinearidade.

- presente conjunto de dados são provenientes dos exames clinicos, antropométricos e laboratoriais realizados em 311 gestantes com idades superiores a 20 anos e com idade gestacional entre 21 e 28 semanas. As pacientes foram acompanhadas no pré-natal geral do Hospital Escola da UFPR e foram submetidas ao teste de tolerancia a glicose CTTG com 75 gramas de glicose como preconizado pela organizacão Mundial de Saúde para o diagnóstico de diabete gestacional.

Os pesquisadores desejavam avaliar fatores associados à glicemia de 2 horas, principal exame diagnóstico da diabete gestacional, como $\mathrm{Ca}$ a idade da gestante, (b) o número de gestaçós anteriores, (c) ${ }^{\circ}$ indice de massa corporal, definido como o peso pré-gravidico dividido pelo quadrado da altura, CdS a soma 
83.

das pregas cutâneas, que o o resultado do somatório das medidas das pregas cutäneas tricipal, bicipal, subescapular - supra-iliaca e Ce a relacão cintura-quadril, que razăo entre a circunferencia da cintura dividida pela circunferência do quadril.

A somatória das pregas é uma medida do grau de obesidade das pacientes, enquanto o indice de massa corporal (IMC) a razão cintura-quadril são medidas da distribuicão da gordura corporal. Verificou-se que estas duas últimas medidas eram correlacionadas por medirem a mesma variável de interesse. Portanto, elas poderian ser üteis na ilustracão de um problema do multicolinearidade. Selecionou-se então, para o presente estudo, 60 pacientes que tinham maior grau de correlacăo destas medidas, a fim de evidenciar o problema. Assim, o presente conjunto de dados deve ser compreendido como dados simulados de um problema real, cujos resultados não tem validade clínica.

os dados estão apresentados no apêndice $I$. Todos os cálculos foran realizados no "software" MATLAB.

\subsubsection{O ESTUDO DA MULTICOLINEARIDADE}

A matriz $x_{\text {coxo }}$ foi decomposta en valorés singulares nas matrizes $U_{00 \times 00} S_{\text {o0xo }} Y_{\text {oxo }}^{\prime}$ Para efeito do presente estudo tomou-se a seguinte decomposicão: 
84.

$$
X_{\sigma D \times \sigma}=U_{\sigma 0 \times \sigma} S_{\sigma \times \sigma} V_{\sigma \times \sigma}^{0}
$$

Por simplicidade estas matrizes serão denomiradas simplesmente $U, S$ e $v$ A matriz $U$ de autovetores ortonormais está apresentada no apêndice $Z$. As matrizes $S \in Y$ são as que seguem:

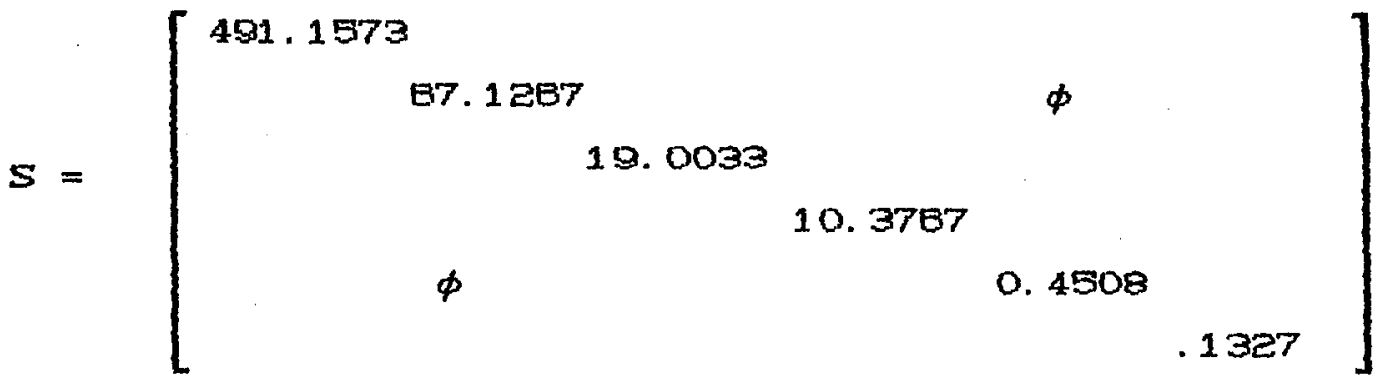

$$
\begin{aligned}
& \gamma=\left[\begin{array}{rrrrrr}
.0155 & -.0178 & .0297 & -.0013 & .0965 & -.0739 \\
.3972 & -.7150 & -.5462 & -.1808 & -.0029 & .0000 \\
.0223 & -.0750 & -.2081 & .9750 & .0058 & -.0000 \\
.3408 & -.4602 & .8077 & .1294 & -.0400 & -.0354 \\
.8516 & .5203 & -.0541 & .0069 & -.0020 & .0002 \\
.0131 & -.0177 & .0309 & .0045 & .0725 & .0965
\end{array}\right]
\end{aligned}
$$

A DVS da matriz $x$ fornece em primeira anălise o número de condicăo. Quanto maior for o número de condicăo mais mal condicionada será a matriz. Para o exemplo em questão:

$n=\frac{s_{\max }}{s_{\min }}=\frac{491.1573}{0.1327}=3.701 .26:=3.7 \times 10^{3}$

Se houvesse exata dependência 11 near entre 
89.

colunas de $X$ haveria pelo menos um valor singular igual a zero. O grau de mal condicionamento depende, no entanto, de quanto é pequeno o menor valor singular em relacão ao maior. E ainda, determinar o que pode ser considerado um número de condição grande, que degrade as estimativas da regressão depende da experiência empirica do pesquisador.

$$
\text { Pode-se, ainda, definir-se números de }
$$

condiç̃o intermediários:

$$
\eta=\frac{s_{\max }}{s_{k}}
$$

onde $k$ indica o $k$-b́simo valor singular da matriz.

E assim, se mais do que um nümero de condicão for considerado alto, haverá então, mais do que uma dependência linear ou de uma "quase" dependência linear.

Una forma de complementar esta informacão. como indicativo de quase dependência é através da observaçăo de como a variancia estimada de cada coeficiente de regressão pode ser decomposto em uma soma de termos cada um associado com um valor singulat, for necendo significado para a determinação de qual quase dependência degrada cada variància.

A variância do estimador $K$ É dada por:

$$
\operatorname{Var}\left(\hat{\beta}_{k}\right)=\sigma^{2} \sum_{j} \frac{v_{k j}^{2}}{s_{j}^{2}}
$$


86.

A $k_{i j}$ - ésima proporção da decomposicão da variância $e^{-} a$ proporcão da variância do $k$ - ésimo coeficiente de regressão associado com o j - ésimo componente de sua decomposicão. Esta proporcão é calculada como segue:

$$
\phi_{k j}=\frac{v_{k j}^{2}}{s_{j}^{2}} \quad \text { } \phi_{k}=\sum_{j=1}^{P} \phi_{k j}
$$

Então, as proporcốes da decomposição da variância são dadas por:

$$
\pi_{j k}=\frac{\phi_{k j}}{\phi_{k}}, k, j=1, \ldots, p
$$

As proporç̃os da decomposicão da variancia para o exemplo são dadas abaixo:

v. Singular Proporcões das variâncias de Número de associado $\hat{\beta}_{2} \hat{\beta}_{2} \hat{\beta}_{3} \hat{\beta}_{4} \hat{\beta}_{3} \hat{\beta}_{0}$ Condicão

\begin{tabular}{llllllll}
\hline$s_{4}$ & .00 & .00 & .00 & .00 & .03 & .00 & 1.00 \\
$s_{2}$ & .00 & .09 & .00 & .00 & .62 & .00 & 7.32 \\
$s_{3}$ & .00 & .04 & .01 & .02 & .12 & .00 & 25.83 \\
$s_{4}$ & .00 & .24 & .97 & .00 & .00 & .00 & 47.33 \\
$s_{s}$ & .94 & .03 & .02 & .10 & .20 & .00 & 1089.52 \\
$s_{a}$ & .00 & .00 & .00 & .88 & .02 & 1.00 & 3701.28
\end{tabular}


87.

Esperava-se que o menor valor singular so associado com a dependência linear entre $x_{4}$ e $X_{a}$ deva dominar várias variäneias, pelo monos aquolas das duas variáveis envolvidas. $E$ este $\dot{e} 0$ caso, 0 componente associado com $s_{\text {o }}$ responsável por virtualmente toda variäncia de $\hat{\beta}_{0}$ grando parte de $\hat{\beta}_{4}$.

A ortogonalidade das outras quatro col unas de X, para as duas varláveis envol vidas na quase dependência, isolaram seus coeficientes estimados do efeito da colinearidade. Observa-se, que os componentes dessas quatro variâncias associados com $s_{0}$ săo bastante pequenos, $0.0 B$, $0.00,0.00$ 0.02. En teoria esses componentes deveriam ser iguais a zero.

A análise ajuda a determinar quais estimadores da regressão são degradados pela presenca de colinearidade, mas também, quais não săo afetados adversamente.

Em sintese, a deteccão de multicolinearidade pode ser avaliada através da verificacão da dupla condicão: 1 a) um valor singular que se julga ter alto número de condição, o qual é associado com eas altas proporcôes da decomposicão da variancia para dois ou mais coeficientes das variâncias de regressão.

Foi visto que um valor. singular igual a zero implica em colinearidade perfelta entre colunas de X. Neste exemplo, a condicão de colinearidade não é definida 
88.

exatamente. Agui o hiper-plano a ser determinado pelo modelo de regiressão, não rotaciona $1 \mathrm{i}$ remente em torno do lugar geométrico deseritor da condicão de colinearldade a estimativa de $\dot{y}$, pode ser determinada para qualquer novo ponto $x$. No entanto, a exata posição do hiperplano é conhecida de forma pobre, exceto na exata vizinhanca da interseção do hiperplano com a projecão vertical do 1 ugar geométrico determi nado pela condicăo de multicolinearidade.

o novo ponto pode ser expresso pela sua DVS

$$
x=u S v
$$

onde $x$ e são vetores de $P$ elementos. Da equacão acima deri va-se,

$$
\begin{gathered}
u=x y s^{-1}, \text { ent.ão } \\
\hat{y}=u \hat{\alpha} \Rightarrow \operatorname{var}(\hat{y})=\alpha^{2} \sum_{j=1}^{p} u_{j}^{2}
\end{gathered}
$$

Esta equação mostra que um grande componente do vetor $u$ pode fazer crescer substancialmente a variância de $\hat{y}$.

$$
\text { Investigar-se-a agora sob quais }
$$
circunstâncias o vetor u pode ter grandes componentes.

$$
\text { De } X=U S V^{\prime} \text { obtém-se US }=X Y, \text { e } S \text { será }
$$
dividida em duas sub-matrizes, $S_{A}$ e $S_{B}, S_{B}$ o autovalor considerado menor que os outros.

$$
\text { Apesar de } S_{S} \text { ser pequeno e próximo de } s_{\sigma} \text { ele }
$$
pertencerá à matriz $S_{\mathbf{A}}$ por não ter apresentado problema na 
89.

análise da matriz da decomposicão da proporcão das variâncias.

$$
\begin{aligned}
& S_{A}=\operatorname{diag}(491,157367.126719 .00330 .376700 .4508) \\
& S_{B}=0.1327
\end{aligned}
$$

A equacão US $=X Y$ pode ser decomposta em

$$
\left.\left[\begin{array}{c}
S_{A} \\
0
\end{array}\right] U\left[\begin{array}{c}
0 \\
S_{B}
\end{array}\right]\right]=\left[\begin{array}{ll}
X Y_{A} & X Y_{B}
\end{array}\right]
$$

os valores pequenos em $X V_{B}$ implicam que $X V_{B} \cong 0$.

Esta é a condição imposta à matriz $x$, que representa uma relacão linear entre as col unas de $X$.

$$
x v_{z}=x\left[\begin{array}{r}
-.0739 \\
.0000 \\
-.0000 \\
-.0354 \\
.0002 \\
.0965
\end{array}\right] \cong 0
$$

$-.0739-0.0354 x_{4}+.0002 x_{5}+.9908 x_{0} \cong 0$

Esta a equacăo do hiper-plano em torno do qual se define a mul ticolinearidade.

Retornando ao problema do predicão para um novo ponto, então $u=C \times v_{A} \times v_{B} \supset S^{-1}$ onde o último elemento de $u$ provém do produto $\quad x v_{B} S_{B}^{-1}$. 
90.

Como $s_{0}$ é muito pequeno, 0 seu reciproco $s_{0}^{-1}$ é muito grandé, ocasionando inflacăo na variancia de $\hat{y}$, porque o valor de u tambím será muito grande, a menos de pontos de $x$ que satifacam a condi fão de quase-col i nearidade da matriz $X$.

o problema central da multicolinearidade, quando visto do ponto de vista da predicão é observar que quanto mals longe o novo ponto estiver da condicão de multicolinearidade, maior será a variáncia de $\hat{y}$, ou seja, pior será a precisão do valor predito.

Para o exemplo en questão

$$
\left.\hat{y}=u \hat{\alpha}=\times C V_{A} x S_{A}^{-1}\right) \hat{\alpha} J
$$

$$
\hat{y}=x\left[\begin{array}{r}
170.4780 \\
2.3887 \\
-1.6278 \\
1.2610 \\
.8305 \\
-212.3061
\end{array}\right]
$$

No caso de "quase-colinearidade" a variancia de $\hat{y}$ cresce drasticamente para pontos fora do sub-espaco de $\mathbf{x}$ definido pela condicão de multicolinearidade. Poderse então, pensar na obtencão de estimadores mais precisos com o sacrificio da condicão de não-vicio do estimador $\hat{y}$, o que \& conhecido como estimacăo viciada. o método diretamente 
91 .

associado com a DVS \& a técnica de regressão por componentes principais.

$$
\text { Seja } y=\sum_{j=1}^{p-1} u_{j} \hat{\alpha}_{j} \text { o estimador viciado de } y \text { sem a }
$$

preocupacão se a condicão $\times V_{B}=0$ é satisfeita ou não. Esta equaçăo chamada de "equacão de predicão viciada por compontentes principais".

A razão para consider tal estimativa - a reducão da variância da estimativa que a acompanha.

Tem-se,

$$
\operatorname{Var}\left(\ddot{y} \supset \operatorname{Var}\left(\sum_{j=1}^{p} u_{j} \hat{a}_{j}\right)=\alpha^{2} \sum_{j=1}^{p} u_{j}^{2}\right.
$$

,

$$
\operatorname{Var}\left(\ddot { y } \supset \operatorname { V a r } \left(\sum_{j=1}^{p-1} u_{j} \hat{\alpha}_{j} j=\sigma^{2} \sum_{j=1}^{p-1} u_{j}^{2}\right.\right.
$$

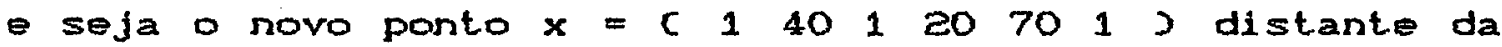
condi cão de coli nearidade.

Para este ponto

$$
\begin{gathered}
u=x\left(v S^{-1}=\right. \\
=6.1336-.0523-.0785-.1018-.1328-.6028)
\end{gathered}
$$

As variảncia das estimativas são 
92.

$\begin{aligned} \operatorname{Var}(\hat{y})= & 3.3810 \alpha^{2} \text { e } \operatorname{Var}\left[\tilde{y} y=0.4180 \alpha^{2}\right. \\ & \text { Observa-se então que a variância do estimador }\end{aligned}$ viciado é cerca de oito vezes menor que a variancia do estimador não viciado. A forma de decisão de qual estimador - melhor, deve ser feita através da avaliacão dos erros médios quadrăticos das estimativas. Para tanto conforme MANDEL (1982), basta comparar o valor de $\hat{\alpha}_{0}^{z}$ con o valor de $\hat{\sigma}$.

Para o exemplo $\hat{a}_{\sigma}^{2}=884$, 8B62 enquanto $\hat{o}=5.8961$. o que implica que $\hat{y}$ tem menor erro médio quadrático que $\tilde{y}$, apesar de ter maior variância. Isto significa que o vicio para esta estimativa é muito grande o que não recomenda o uso do estimador viciado. 
93.

\section{CONCLUSÖES}

Dentro dos objetivas do presente estudo, as conclusốes são apresentadas com base na revisão de literatura realizada e na aplicação das técnicas ao problema real proposto, considerando suas $11 \mathrm{mitacb́}$ tes:

a) A decomposicâo em valores singulares da matriz do modelo propicia algoritmos estáveis para a leitura de um problema em modelos lineares e alëm disso, auxilia a compreender toda a natureza do problema.

b) A avaliacão de um problema do particular modelo de regressão com mal-condicionamento da matriz do modelo deve ser feita através da avaliacão da origem do problema, das suas conseguências, das formas de diagnóstico e da análise das possíveis soluçôes de contorno.

c) O problema de mal-condicionamento da matriz é essencialmente um problema numérico, e daí a necessidade de algoritmos estáveis para seu estudo.

d) A deteccão do problema de mal-condiconamento da matriz X $e$ fundamental para o estudo 
94.

da regressão, mas mais importante é a avaliacão da extensão do problema de suas consequiencias.

e) A análise por componentes principais pode sugeris a utilizacão de un estimador viciado, por ter menor variäncia que um estimador não viciado. "Negociar" o vício com a inflaçăo da variância 0 ponto central na escolha do melhor estimador.

f) A análise por componentes principais não elimina completamente o froblema da selecão de variáveis explicativas e portanto do modelo a ser ut 1 i zado.

g) 0 número de condição associado à decomposição das proporcỗes das variâncias, são formas importantes para o diagnóstico da multicolinearidade.

h) A presenca de multicolinearidade pode não ser importante na estimacão de novas observacốes que estejam próximas à condição de colinearidade.

1) A avaliação da estimabilidade se dá no espaco linha da matriz de delineamento, e se pode pensar em quase-estimabilidade, quando $\lambda$ estiver próximo deste espaco.

j) Mesmo se o número de condiçăo for grande, por exemplo, na ordem de $10^{3}$, isto não implica necessariamente em problemas para a estimação.

h) Ainda que a proporcão da variáncia de um coeficiente, associado a um valor singular pequeno, 
95.

domine a variânçia daquele coeficiente, como en $\hat{\beta}_{1} s_{5}$, a variância do estimador pode não ser grande e o problema de multicoli nearidade pode não ser importante.

$$
\text { i) As variáveis IMC e relacão }
$$

cintura-quadril são variáveis que explicam a distribuicão da gordura corporal. A colinearidade entre elas indica a fidedignidade das medi das. 
96.

\section{REFERENCIAS BIBLIOGRAFICAS}

AOKI,R. Uma possivel solucão para o problema de mal condicionamento da matriz do modelo de regressão. Campinas, 1992. 85 p. CMestrado - Instituto de Matemática, Estatistica e Ciências da Computacãor UNI CAMPS.

BELSLEY,D.A. ; KUH,E.; WELSCH,R.E. Regression diagnostics: Identifying influential data and sources off collinearity. New York, John Wiley \& Sons, 1980. 29ep.

EEN-ISRAEL,A. \& GREVILLE, T.N.E. Generalizd inverses : theory and applications. New York, John Wiley \& Sons, 1974.

CARVALHO, J.F. Modelos lineares sua avaliaç̃o. São Carlos, 1982. 95p. Clivre Docência - Universidade de São Pauloj. . 
97.

CARVALHO FILHO, A.A. A decomposicão da matriz de planejamento por valores singulares em modelos de posto incompleto. Piracicaba, 1987. 118p. CDoutorado - Escola Superior de Agricultura "Luiz de Queiroz"

CARVALHO FILHO, A. A. \& IEMMA, A.F. A aplicacão da decomposicão pelo valor singular no estudo da esti mabilidade de functos lineares em modelos de GaussMarkov. Revista de Matemática e Estatistica, São Paulo, 8: $37-44,1990$.

CHATIERJEE,S. \& PRICE,B. Regression analysis bx example. New York, John Wiley \& Sons, 1977. 2e8 p.

CHURCHILL, G. A. A regression estimation method for collinear predictors. Decision Sciences, E: 671-87, 1975.

DRAPPER, N.R. \& SMITH, H. Applied regression analvsis, 2 ed., New York, John Wiley Sons, $1981.710 \mathrm{p}$.

DRYGAS, H. The coordinate-free approach to Gauss-Markov Estimation. Springer-Verlag. Berlin, 1970. $113 \mathrm{p}$.

ECKART, C. \& YOUNG, G. The approximation of a matrix by another og lower rank. Psychometrika, 1:211-18. 1930. 
98.

EUBANK, R.L. \& WEESTER, J.T. The singular-value decomposition as a tool for solving estimability problems. The American Statistician, Alexandria, $39(1): 04-66.1988$.

FARRAR, D.E. \& GLAUBER, R.R. Multicollinearity in regression analysis: the problem revisited. Review of Economics Statistics, 49:92-107, 1967.

FERRARI, F. Estimadores viesados para modelos de regressão em presença de multicolinearidade. Piracicaba, 1989. 127p. CDoutorado - Escola Superior de Agricultura "Luiz de Queiroz" ', USPY

FERRARI, F. \& IEMMA, A.F. Um eritério para a selecão de variáveis na regressão em componentes principais. Revista de Matemática e Estatistica, São Paulo, 으: $101-13,1990$.

FORSYTHE, G. \& MOLER, C.B. Computer solution of linear algebraic systems. Englewood Cliffs, Prentice-Hall, 1967.

Fox, J. Linear statistical models and related methods with applications to social research. New York, Jonh Wiley \& Sons 1984. $449 \mathrm{p}$. 
99.

GOLUB, G.H. Matrix decompositions ans statistical calculations. - In: Statistical computation. R.C. Milton, et alii. Eds Academic Press, New York. 1959.

GOLUE, G.H. \& REINSCH, C. Singular value decomposition and least squares solutions. Numeric Mathematics, Stantfort, 14: 403-20, 1970 .

600D, I.J. Some applications of the singular decomposition of a matrix. Technometrics, Richmond, $11(4): 823: 31,1969$.

GRAYBILL, F.A. Introduction to matrices with application in statistics. Belmont, Wadsworth Publishing Company. 1983. 372 p.

GREENBERG, E. Minimum variance properties of principal components regression. Iournal of the American Statistical Association, Whashington, 706 349: 194-7, 1975.

GUNST, R.F. \& MASON, R. L. Advantages of examining multicollinearities in regression analysis. Biometrics, Ralei gh, 33: 249-80, 1977a.

GUNST, R.F.' \& MASON, R.L. Bi ased estimation in regression: 
100.

An evaluation using mean squared error. Journal of the American Statistcal Association, Washington, 726 3590: $616-28,1977 b$

HALMOS, P.R. Espacos vetoriais de dimensão finita. Rio de Janeiro, Editora Campus, $1978.199 \mathrm{p}$.

HAWKINS, D.M. On the investigation of alternative regression by principal component analysis. Applied Statistics, London, 22: $275-86,1973$.

HOCKING, R.R.; SPEED, F.M. ; LYNN, M.J. A class of biased estimators in innear regression. Technometrics, Richmond, 18( 4):425-37, 1976 .

HOERL, A.E. \& KENMARD, R.W. Ridge regression: Biased estimation for nonorthogonal problems. Technometrics. Richmond, 12(1): 55-68, 1970 a.

HOERL, A.E. \& KENNARD, R. W. Ridge regression: Applications to nonorthogonal problems. Iechnometrics, Richmond, $12(1): 59-82,1970 b$.

IEMMA, A.F. Modelos 1 ineares. Uma introducão para profisstonals da pesquisa agropecuária. 2o Simpósio de Estatística Aplicada à Experimentacão Agronômica e $32^{2}$ 
Reunião da Sociedade Brasileira de Biometria. Londrina $1987,263 \mathrm{p}$

IEMMA, A.F. \& CARVALHO FILHO, A.A. 0 usO da DVS na estimabilidade no modelo linear de Gauss-Markov. Atas da 1 a Escola de Modelos Lineares. São Paulo, 1989. p. $66-74$

JAMES, $W$ Be STEIN, $C$. Estimation with quadratic loss. In: Neyman, J. Proceedings of the fourth Berkelex Symposium vol.1. Berkeley, University of California Fress, 361-79. 1961.

KENDALL, M.G. A course in multivariate analysis. London. Griffin, 1957.

LANCASTER, P. \& JOHMSON, C.R. The theOrY of matrices, New York, Academic Press, 1985.

LAWSON, G. L. B HANSON, R. J. Solving Least Square Problems, Englewood Cliffs, Prentice Hall, 1974. 340p.

LIMA FILHO, E. S. Planejamento de obser varónes adicionais em modelos lineares: a decomposicão em valores singulares da matriz de planejamento e sua utilização. São Carlos, 1981. Bop. Clivre-docência - Universidade de São Paulo). 
102.

MANDEL, J. Use of the singular value decomposition in regression analysis. The American Statistician, Alexandria, $36(1): 15-24,1982$.

MARQUARDT, D. W. Generalized inverses, ridge regression, biased linear estimation and nonlinear estimation. Technometries, Richmond, 126 3):591-612, 1970.

MARQUARDT, D. W. \& SNEE, R. D. Ridge regression in practice. The American Statistician. Alexantria, 29: 3-20, 1975.

MARTENS, H. \& NAES,T. Mutivariate calibration, Now York, John Wiley \& Sons, $1989.419 \mathrm{p}$.

MASON, R.L.; GUNST, R.F. \& MEBSTER,J.T. Regression Analysis and problems of multicollinearity. Communications in Statistics. New York, A3:277-92, 1975.

MATLAB- 386 Based MS-DOS Personal Computers. The Mathworks Inc. Natick. 1990.

matsuo, T. O uso da regressão de cumeeira em experimentos agronómicos. Piracicaba, 1986. 89p. CMestrado - Escola Superior de Agricultura "Luiz de Queiroz" $/$ USP3. 
103.

MAYER,L.S. \& WILKE, T.A. On biased estimation in linear models. Technometrics, Richmond, 15: 497-508.1973.

MONTCOMERY, D.C. \& PECK, E. A. Introduction to linear regression analysis, New York, John Wiley \& Sons, 1981. 504 p. .

MOTA, R.M.S. Caracterizacão dos melhores estimadores lineares não tendencioso no modelo linear geral. São Paulo, 1982. 147 p. CMestrado - Instituto de Matemática e Estatistica, USPS J

NELDER, J. An alternative interpretation of the singular value decomposition in regression. The american statistician, Al exandria, $39613: 63-4,1985$.

NETER, J.; YASSERMAN, W. ; KUTNER, M. H. Applied Iinear regression models, Homewood, Richard D. Irwin, 1983. 547 P.

NOBLE, B. Applied linear algebra, Englewwod Cliffs, Prentice-Hall, 1969.523 p.

ORTEGA, J.M. Matrix theory: a second course, New York, Plenum Press, 1987. 
104.

PALM, R. \& IEMMA, A.F. Quelques alternatives a 1 a régression classique dans le cas de la colinéarité. Revue de Statistigue appliquée. Gembloux, 2r94: 27p. , 1994.

RAO, C.R. Generalization of Markof''s theorem and tests of linear hypotheses. Sankhyä, 7: 9-18, 1945.

RAO, C.R. Linear statistical inference and its applications. New York, John Wiley Sons, 1965. Se2 p.

SEARLE, S.R. Linear models, Now York, John Wiley \& Sons, 1971. S5e p.

SEARLE, S.R. Matrix algebra useful for statistics, Now York, John Wiley \& Sons, $1982.438 p$.

SILVEY, S.D. Multicoliinearity and Imprecise estimation. Journal of the Royal Society, sêrie B. London, 31: 539-52, 1969

SWINDEL, B.F. \& BENEE, F. Instability of regression coefficients illustrated. The american statistician. Al exandria, 28C25: 83-5, 1974.

VAN LOAN, c. Lectures in least squares. Departament of 
105.

Computer Science Cornell University. New York, 1978. $61 \mathrm{p}$.

WEBSTER, J.T.; GUNST, R.F. ; MASON, R.L. Latent root regression analysis. Technometrics. Richmond, $16(4): 513-22,1974$. 
100

6. APENDICE 1 
MATRIZ XIY

\begin{tabular}{|c|c|c|c|c|c|c|}
\hline $\mathrm{x}$ & $x_{2}$ & $x_{3}$ & $x_{4}$ & $x_{5}$ & $x_{a}$ & $Y$ \\
\hline 1 & 21 & 0 & е2. 70 & 47.0 & 0.86 & 108 \\
\hline 1 & 20 & 0 & 24.40 & 81.0 & 0.93 & 118 \\
\hline 1 & 33 & 8 & 2E. 70 & 74.8 & 0.88 & 148 \\
\hline 1 & 32 & 3 & 2R.76 & 36.5 & 0.88 & 110 \\
\hline 1 & 23 & 2 & 24.40 & 47.0 & 0. 92 & 90 \\
\hline 1 & 23 & 0 & 24.70 & 41.0 & 0.96 & 88 \\
\hline 1 & 21 & 1 & 21.50 & 33.0 & 0.86 & 87 \\
\hline 1 & 28 & 0 & 19.20 & 49.5 & 0.75 & 130 \\
\hline 1 & $2 e$ & 0 & 20.00 & 63.5 & 0.78 & 138 \\
\hline 1 & 33 & 1 & 24.30 & 37.0 & 0.92 & 115 \\
\hline 1 & 24 & 3 & 2E. 30 & 43.5 & 0.88 & 101 \\
\hline 1 & 22 & 0 & 24.80 & 43.0 & 0.97 & 85 \\
\hline 1 & 30 & 3 & 25.60 & 36.0 & 0.99 & 83 \\
\hline 1 & 28 & 0 & 22. 80 & 34.0 & 0.86 & 110 \\
\hline 1 & 21 & 1 & 21.64 & 54.0 & 0.85 & 125 \\
\hline 1 & 24 & 0 & e2. 00 & 39.0 & 0.83 & 113 \\
\hline 1 & 21 & 3 & 21.92 & 54.0 & 0.83 & 95 \\
\hline 1 & 33 & 4 & 26.00 & 35.0 & 0.99 & 96 \\
\hline 1 & $\mathrm{ez}$ & 1 & 2e. 48 & 27.0 & 0.85 & 92 \\
\hline 1 & 27 & 2 & 22.55 & 50.0 & 0.85 & 120 \\
\hline 1 & 40 & 4 & 23.55 & 28.5 & 0. 91 & 125 \\
\hline 1 & 23 & 3 & 20.41 & 59.5 & 0.81 & 123 \\
\hline 1 & 24 & 0 & 20.75 & 49.5 & 0.78 & 132 \\
\hline 1 & 25 & 0 & 22. OB & 46. 0 & 0.87 & 110 \\
\hline 1 & 27 & 3 & 21.70 & 60.5 & 0.81 & 130 \\
\hline 1 & 28 & 2 & 23.11 & 32.5 & 0.89 & 101 \\
\hline 1 & $2 e$ & 1 & 21.28 & 35.5 & 0.79 & 111 \\
\hline 1 & 23 & 1 & 21.73 & 59.5 & 0.84 & 125 \\
\hline 1 & 30 & 0 & 20.69 & 38.0 & 0.80 & 128 \\
\hline 1 & 21 & 1 & 2e. 30 & 70.5 & 0.84 & 130 \\
\hline 1 & 23 & 1 & 21.70 & 77.5 & 0.85 & 120 \\
\hline 1 & 28 & 1 & 23.24 & 40.0 & 0.88 & 112 \\
\hline 1 & 25 & 1 & 20.94 & 34.5 & 0.83 & 100 \\
\hline 1 & 22 & 1 & 22. 90 & 80.0 & 0.88 & 115 \\
\hline 1 & 30 & 0 & 2e. 10 & 67.8 & 0.82 & 140 \\
\hline 1 & 28 & 3 & 20.10 & 63.7 & 0.75 & 138 \\
\hline 1 & 20 & 0 & 21.80 & Be. 0 & 0.80 & 115 \\
\hline 1 & 23 & 1 & 21.90 & Bo. 0 & 0.87 & 118 \\
\hline 1 & 27 & 1 & 19.50 & 59.4 & 0.77 & 146 \\
\hline 1 & 27 & 0 & 21.40 & 60.5 & 0.81 & 144 \\
\hline 1 & 20 & 1 & 20.50 & 59.5 & 0.81 & 144 \\
\hline 1 & $2 e$ & 3 & 2E.20 & 59.6 & 0.83 & 124 \\
\hline 1 & 20 & 0 & 20.00 & 65.0 & 0.78 & 135 \\
\hline 1 & 28 & 1 & 22. 80 & 80.0 & 0.86 & 158 \\
\hline 1 & 25 & 0 & 21.60 & 70.5 & 0.83 & 145 \\
\hline 1 & 27 & 1 & 22.29 & 68.0 & 0.85 & 143 \\
\hline 1 & 25 & 5 & 20.00 & 41.5 & 0.80 & 111 \\
\hline
\end{tabular}




\section{MATRIZ XIY}

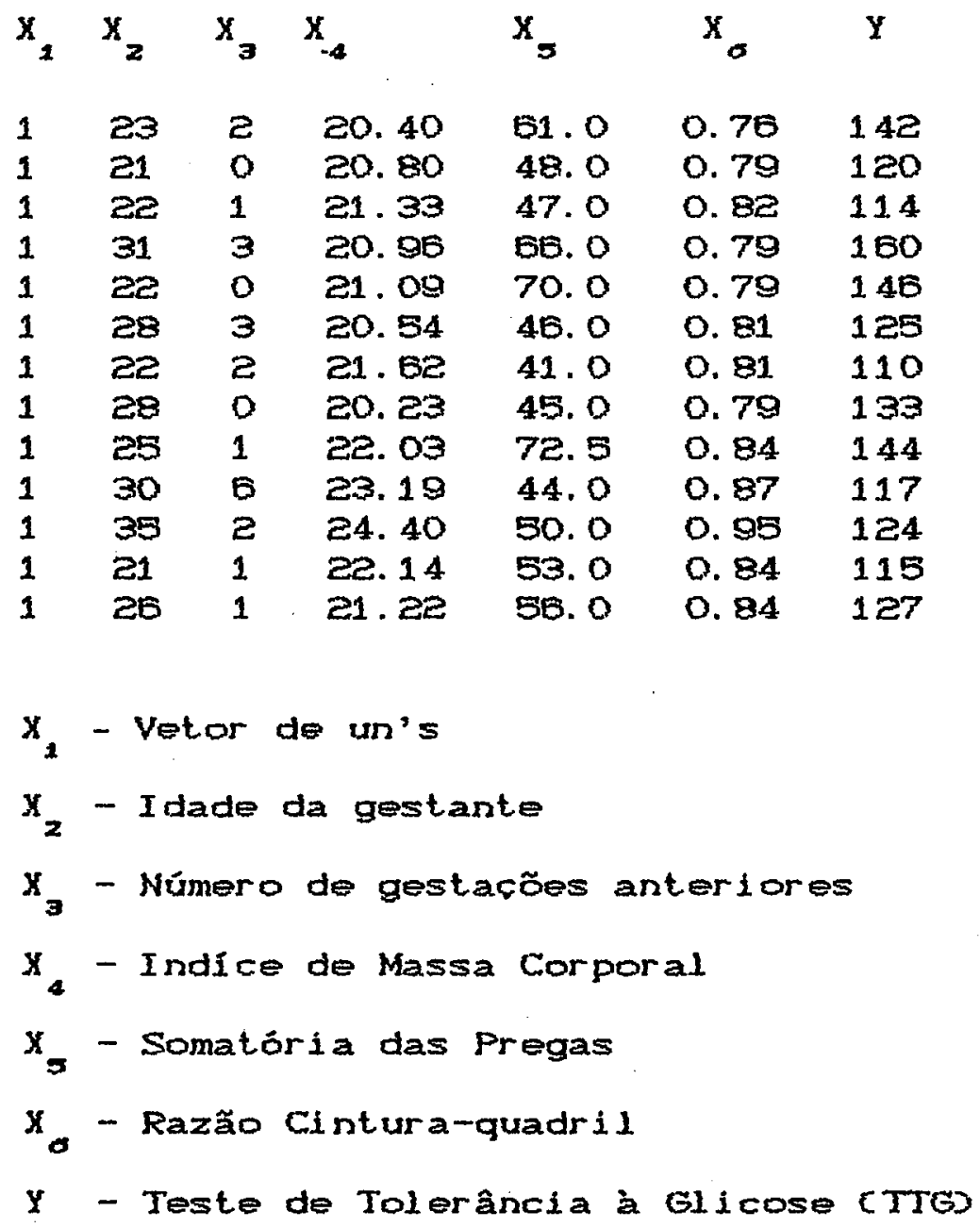


109

7. APENNDICE 2 
110.

MATRIZ U

\begin{tabular}{|c|c|c|c|c|c|}
\hline .1143 & -.0155 & 2058 & -.0509 & -.0153 & -.0856 \\
\hline .1785 & .1831 & .0198 & -.0941 & -.3407 & .0327 \\
\hline .1719 & .0531 & -. 2975 & .3223 & $-.13 \mathrm{BB}$ & .1031 \\
\hline .1051 & -.2178 & -.1053 & .0333 & -.0027 & .0374 \\
\hline .1172 & -.0507 & .1987 & .1235 & -.1430 & -.0881 \\
\hline .1080 & -.0971 & 2537 & -.0847 & $-.1 \mathrm{EZT}$ & .1248 \\
\hline . O892 & -.1169 & .1910 & .0188 & .1673 & . 2101 \\
\hline .1202 & -.0254 & -.0953 & -.1799 & .2343 &. OES5 \\
\hline .1418 & $.1 \mathrm{ZOE}$ & .0085 & -.0910 & .1308 & . O557 \\
\hline .1078 & -.2330 & -.0483 & -.1525 & -.1674 & -.0717 \\
\hline .1105 & -.0752 & .0815 & .1715 & .0584 & $.1 \mathrm{BPZ}$ \\
\hline .1098 & -.0710 & . 2799 & -.0447 & -.1726 & .1756 \\
\hline $.104 B$ & -.2199 & .0748 & .1033 & -. 2e20 & .1049 \\
\hline .0975 & -.1915 & .0526 & -.1801 & -.0108 & -.1274 \\
\hline .1431 & .1224 & . OP24 & .0412 & .0134 & .1443 \\
\hline .1023 & -.1047 & .1167 & -.1172 & .0587 & -.1339 \\
\hline $.12 \mathrm{CBO}$ & .0407 & .1161 & . 2259 & .0581 & -.0941 \\
\hline .1057 & -. 2Bas & -.0020 & .1493 & -.2596 & -.0025 \\
\hline .0803 & -.1808 & . 2241 & .0096 & .0992 & $-.1 \mathrm{ZB1}$ \\
\hline .1244 & -.0581 & -.0008 & .0340 & -.0391 & -.1421 \\
\hline .0983 & -.3716 & $-.28 B 0$ & -.0074 & -.0708 & .0435 \\
\hline .1361 & .0724 & -.0241 & .1759 & .1493 & $.1 \mathrm{BE3}$ \\
\hline .1197 & -.0147 & .0281 & -.1258 & .1144 & $-.1 \mathrm{BCZ}$ \\
\hline .1153 & -.0616 & .0678 & -.1289 & . OEOO & .1548 \\
\hline .1420 & .0287 & -.0878 & .1230 & .0043 & -.1755 \\
\hline .0952 & -.2075 & .0490 & .0107 & -.0011 & .0130 \\
\hline .0942 & -.1067 & .1444 & .0003 & .1578 & -.2476 \\
\hline .1369 & .0056 & .0539 & .0045 & .0112 & .0398 \\
\hline .1040 & -.1673 & -.1081 & -.2386 & .1380 & -.0094 \\
\hline .1548 & .1882 & .0980 & .0537 & -.0761 & -.0984 \\
\hline $.1 \mathrm{B81}$ & .2053 & -.0080 & .0181 & -.0857 & $.14 \mathrm{ES}$ \\
\hline .1082 & -.1492 & .0402 & -.0767 & -.0809 & -.0868 \\
\hline .0947 & -.1441 & .0471 & -.0588 & .1790 & .1432 \\
\hline .1378 & .0721 & .1308 & .0388 & -.0821 & .0285 \\
\hline .1569 & .0524 & -.1479 & -.2013 & -.1195 & -.1965 \\
\hline .1472 & .0530 & -.1953 & .0878 & .1159 & -.1949 \\
\hline .1387 & .1189 & .1372 & -.0372 & .0212 & .2274 \\
\hline .1379 & .0583 & .0595 & .0069 & -.0013 & .2205 \\
\hline .1385 & .0375 & -.1556 & -.0931 & .1726. & .1098 \\
\hline .1416 & .0341 & -.0675 & -.1626 & -.0075 & -.0950 \\
\hline .1409 & .0101 & -.1709 & -.1183 & $.078 B$ & .1442 \\
\hline .1367 & $.071 B$ & .0804 & .2157 & -.0005 & -.1812 \\
\hline $.14 \mathrm{ZB}$ & .1532 & .0589 & -.0552 & .1370 & .0572 \\
\hline . 1771 & .1883 & -.1219 & -.0581 & $-.187 \theta$ & -.0138 \\
\hline .1975 & .1316 & -.0352 & -.1180 & -.0542 & .0148 \\
\hline .1553 & .0850 & -.0659 & -.0525 & -.1011 & -.0223 \\
\hline .1063 & -.0878 & -.0603 & .3119 & .2780 & .1771 \\
\hline .1387 & .0852 & -.0187 & .0828 & .1225 & -.2046 \\
\hline .114 & .0053 & .1215 & -.0739 & .1377 & -.1032 \\
\hline .1142 & 0179 & 1078 & 0086 & .1063 & 0204 \\
\hline
\end{tabular}


MATRIZ U

$\begin{array}{lrrrrr}.1542 & .0338 & -.0326 & .0478 & .0162 & -.1200 \\ .1538 & .1631 & .0309 & -.0731 & .0063 & -.1514 \\ .1168 & -.0884 & -.1168 & .0815 & .1663 & .1152 \\ .1040 & -.0875 & .1294 & .1021 & .1189 & -.1810 \\ .1148 & -.0886 & -.0938 & -.0049 & .1568 & .0468 \\ .1813 & .1430 & -.0348 & -.0179 & -.0870 & -.0227 \\ .1170 & -.1447 & -.0877 & . .3603 & -.0248 & -.1436 \\ .1321 & -.1553 & -.1563 & -.0834 & -.2302 & .1444 \\ .1243 & .0337 & .1508 & .0401 & .0170 & -.0787 \\ .1329 & .0100 & -.0422 & -.0564 & .0529 & .1721\end{array}$

